\title{
Genome-Wide Characterization of Peptidyl-Prolyl Cis-Trans Isomerases in Penicillium and Their Regulation By Salt Stress in a Halotolerant P. Oxalicum
}

\author{
Mangaljeet Singh \\ Guru Nanak Dev University \\ Kirandeep Kaur \\ Guru Nanak Dev University \\ Avinash Sharma \\ Guru Nanak Dev University \\ Rajvir Kaur \\ Guru Nanak Dev University \\ Dimple Joshi \\ Guru Nanak Dev University \\ Megha Chatterji \\ Guru Nanak Dev University \\ Iman Dandapath \\ Guru Nanak Dev University \\ Amarjeet Kaur \\ Guru Nanak Dev University \\ Prabhjeet Singh ( $\sim$ singhprabhjeet62@gmail.com) \\ Guru Nanak Dev University
}

\section{Research Article}

Keywords: Peptidyl-prolyl cis-trans isomerases (PPlases), Penicillium spp, Penicillium oxalicum

Posted Date: February 23rd, 2021

DOI: https://doi.org/10.21203/rs.3.rs-223100/v1

License: (c) (i) This work is licensed under a Creative Commons Attribution 4.0 International License. Read Full License 


\section{Abstract}

Peptidyl-prolyl cis-trans isomerases (PPlases) are the only class of enzymes capable of cis-trans isomerization of the prolyl peptide bond. The PPlases, comprising of different families viz., cyclophilins, FK506-binding proteins (FKBPs), parvulins and protein phosphatase 2A phosphatase activators (PTPAs), play essential roles in different cellular processes. Though PPlase gene families have been characterized in different organisms, information regarding these proteins lacks in Penicillium species, which are commercially an important fungi group. In this study, we carried out genome-wide analysis of PPlases in different Penicillium spp. and investigated their regulation by salt stress in a halotolerant strain of Penicillium oxalicum. These analyses revealed that the number of genes encoding cyclophilins, FKBPs, parvulins and PTPAs in Penicillium spp. varies between 7-11, 2-5, 1-2, and 1-2, respectively. The halotolerant $P$. oxalicum depicted significant enhancement in the mycelial PPlase activity in the presence of $15 \% \mathrm{NaCl}$, thus, highlighting the role of these enzymes in salt stress adaptation. The PPlase activity in P. oxalicum was associated with the expression of PoxCYP18, PoxCYP23, PoxCYP41, PoxFKBP12-2, and PoxFKBP52 genes. Characterization of PPlases in Penicillium spp. will provide an important database for understanding their cellular functions and might facilitate their applications in industrial processes through biotechnological interventions.

\section{Introduction}

The peptide bonds not preceding proline are almost always trans in folded proteins, but about 10-15\% of all Xaa-Pro (Xaa: other bulky amino groups preceding proline) peptide bonds show cis conformation ${ }^{1,2}$. Conversion of Xaa-Pro bond from cis to trans conformation, imperative for the correct folding of proteins, is a slow rate-limiting step and requires intervention of PPlases ${ }^{3}$. The PPlases are categorized into different classes viz., cyclophilins, FKBPs and PTPAs. While cyclophilins bind cyclosporin A (CsA), the FKBPs show affinity for FK506 and rapamycin. The PPlase activity of parvulins is sensitive only to juglone and is not affected by either CsA or FK506 ${ }^{4}$. The PPlases that contain both cyclophilin and FKBP domains have also been reported ${ }^{5}$. The PTPAs also exhibit PPlase activity, but are structurally and biochemically distinct from cyclophilins, FKBPs and parvulins and, hence categorized as a different class ${ }^{6}$.

The cyclophilins, defined by a conserved cyclophilin-like domain (CLD), are ubiquitously observed in bacteria to higher organisms ${ }^{7}$, and are encoded by large gene families, with the number ranging from eight in Saccharomyces cerevisiae to 19 in humans, 89 in wheat and 91 in Brassica napus ${ }^{8-12}$. The FKBPs also constitute a multigene family. Compared to four in S. cerevisiae, up to 18 and 29 different family members have been reported in humans and rice, respectively ${ }^{13-15}$. A characteristic feature of FKBPs is the presence of an approximately 110 amino acid (AA) long FK506-binding domain (FKBD) that acts as a receptor of FK506 and rapamycin. The repertoires of parvulins and PTPAs are limited, with only one and three parvulins reported in Escherichia coli and humans, respectively ${ }^{4,16-18}$. Likewise, only one PTPA gene was observed in humans, compared to two in S. cerevisiae $^{6,19}$.

Besides being implicated in several essential cellular processes, such as receptor complex stabilization, plant growth and development, RNA processing, etc., several cyclophilins have also been implicated in abiotic stress adaptation ${ }^{7,20-26}$. Role in abiotic stress response has also been demonstrated for FKBPs such as WFKBP77 and VFFKBP15 in wheat and Vicia faba, respectively, and Sce.FKBP12 in Scenedesmus sp. ${ }^{27-29}$. These observations imply that PPlase genes may serve as suitable candidates for enhancing the abiotic stress tolerance of microbes and plants for industrial processes and agricultural applications and, thus, warrant further investigations.

Eco-friendly solutions for industrial production of different biomolecules entail the application of microbial cells. To this purpose, Penicillium has long been used for the production of specialized cheese, antibiotics, enzymes and a wide range of other biologically active metabolites ${ }^{30-32}$. However, exposure to $\mathrm{NaCl}$, an integral component of the media used for growth during various fermentation processes, often results in salt stress and adversely affects the growth and metabolism of microbial cells due to $\mathrm{Na}^{2+}$ toxicity and osmotic stress. Further, the sensitivity to salt stress also limits the use of seawater as a sustainable substitute for freshwater in industrial processes ${ }^{33}$. Therefore, to develop viable bioprocesses under high salt conditions, it is imperative that the role of PPlases in salt stress tolerance be investigated in the microbial strains.

Halotolerance in fungi is attributed to several different mechanisms viz., maintenance of plasma membrane fluidity and $\mathrm{Na}^{+}$homeostasis, accumulation of compatible osmolytes, and expression of genes implicated in mitochondrial biogenesis and metabolism ${ }^{34-37}$. Synthesis of chaperones such as heat shock proteins and PPlases also provides protection against stress-induced damage to the cell $7,25,26,38,39$. Though PPlases have been characterized in several fungi ${ }^{40}$, and implicated in stress response in Aspergillus and Geobacillus ${ }^{41-43}$, information about these proteins is lacking in Penicillium. Therefore, in the present study, we carried out in silico characterization of cyclophilin, FKBP, parvulin and PTPA gene families in Penicillium spp. and analysed the effect of salt stress on intracellular PPlase activity and expression of these genes in a halotolerant strain of $P$. oxalicum that is able to grow in the presence of up to $15 \%$ salt $(\mathrm{NaCl})$. These findings revealed that the number of cyclophilins, FKBPs, parvulins, and PTPA in different Penicillium species vary between 7-11, 2-5, 1-2 and 1-2, respectively. The halotolerant isolate of $P$. oxalicum exhibited significant enhancement in the mycelial PPlase activity under salt stress which was also accompanied by a substantial increase in the expression of a cyclophilin gene, PoxCYP18. These studies are the first to identify and characterize different PPlase gene families in Penicillium and their possible role in salt stress response. The results of these investigations will provide an important database for further elucidation of the role of PPlases in different aspects of growth and development in Penicillium which may lead to their potential exploitation for different commercial processes.

\section{Materials And Methods}

The halotolerant fungal strain HP1, used in this study, was isolated from the leaves of healthy plants of Citrus limon and identified by the Microbial Type Culture Collection (MTCC) Chandigarh, India. The culture was identified using microscopic and molecular methods. The slide culturing technique was performed to determine the microscopic characters of the fungus and its morphological characterization according to the standard taxonomic key characters. Identification of the culture on the molecular basis was carried out by amplification of the internal transcribed spacer (ITS) region containing 5.8S rRNA that 
yielded an amplicon of $338 \mathrm{bp}$. Sequencing of the amplicon and its subsequent analysis by basic local alignment search tool (BLAST) on the National Center for Biotechnology Information (NCBI) server revealed its maximum similarity with P. oxalicum (NR_121232.1) (Supplementary Fig. S11).

The mycelial production was carried out by inoculating one plug ( $8 \mathrm{~mm}$ diameter) of actively growing fungal culture in $250 \mathrm{ml}$ Erlenmeyer flasks containing 50 $\mathrm{ml}$ Sabouraud production medium that either lacked or contained $\mathrm{NaCl}(15 \%)$. The inoculated flasks were incubated at $30^{\circ} \mathrm{C}$ for 10 days on a rotary shaker at $180 \mathrm{rpm}$ and withdrawn at different time intervals for different analyses. For dry weight estimations, the cultures (50 $\mathrm{ml}$ ) were filtered through Millipore membrane filters $(0.45 \mathrm{~mm})$ under vacuum and dried at $80^{\circ} \mathrm{C}$ until constant weight. The growth curves were constructed from the results obtained from two independent experiments, each carried out in triplicate, and were used to determine the final fungal biomass yield. The effect of salt on colony diameter was analyzed by inoculating Sabouraud agar plates containing $15 \% \mathrm{NaCl}$ with fungal culture, followed by incubation at $30^{\circ} \mathrm{C}$. The fungal growth was monitored daily for ten days by measuring the diameters of individual colonies.

\section{Estimation of peptidyl-prolyl cis-trans isomerase (PPlase) activity}

The total soluble proteins were extracted from the filtered mycelia of $P$. oxalicum by adding lysis buffer [50 mm Tris-Cl, $150 \mathrm{~mm} \mathrm{NaCl,} 1 \mathrm{~mm} \mathrm{EDTA}$ (pH 8), $10 \%$ Glycerol, $1 \mathrm{~mm}$ phenylmethylsulfonyl fluoride] followed by sonication with $10 \mathrm{~s}$ on and $5 \mathrm{~s}$ off for $5 \mathrm{~min}$ at $4^{\circ} \mathrm{C}$. The homogenate was centrifuged at $6500 \mathrm{rpm}$ for $30 \mathrm{~min}$ at $4^{\circ} \mathrm{C}$ and the supernatant was collected and stored at $-20^{\circ} \mathrm{C}$ after filtering through $0.45 \mathrm{um}$ filters. The total soluble proteins were estimated according to Bradford's method ${ }^{80}$ using bovine serum albumin as the standard. The PPlase activity in the crude extracts was estimated by a chymotrypsinbased coupled reaction at $15^{\circ} \mathrm{C}$ for $360 \mathrm{~s}^{81}$. The $1 \mathrm{ml}$ assay mixture contained $80 \mu \mathrm{M}$ succinyl-ala-ala-pro-phe-p-nitroanilidine as test peptide, assay buffer [50 $\mathrm{mM}$ HEPES (pH 8.0), $150 \mathrm{mM} \mathrm{NaCl}, 0.05 \%$ Triton X-100] and different concentrations of the crude protein. The reaction was initiated by addition of chymotrypsin at a final concentration of $300 \mu \mathrm{g} / \mathrm{ml}$. The absorbance change at $390 \mathrm{~nm}$ was monitored at $15^{\circ} \mathrm{C}$ by using Spectrophotometer (Perkin-Elmer Lambda Bio 25) equipped with Peltier temperature control system. The cyclophilin- and FKBP-associated PPlase activities were determined by the extent of inhibition of reaction in the presence of the specific inhibitors CsA and FK506, respectively. The inhibitors were added to the assay mix 30 min before starting the reaction and incubated at $4^{\circ} \mathrm{C}$. The PPlase activity was calculated as the product of the difference in the catalysed and uncatalysed first-order rate constants (derived from the kinetics of the absorbance change at $390 \mathrm{~nm}$ ) and the amount of substrate in each reaction.

\section{Bioinformatics analysis}

The amino acid sequences of cyclophilins, FKBPs, parvulins and PTPAs of 24 different Penicillium spp.were retrieved from the NCBI server (http://www.ncbi.nlm.nih.gov/) by basic local alignment search tool BLAST using the human cyclophilin A (hCYPA), FKBP12 (hFKBP12) and parvulins (hPAR14/hPIN1), and PTPAs (YPA1/YPA2) of $S$. cerevisiae as a query. The domains in the putative PPlase proteins were identified with CDD (https://www.ncbi.nlm.nih.gov/Structure/cdd/wrpsb.cgi), PFAM (http://pfam.xfam.org), Prosite (https://prosite.expasy.org/) and SMART (http://smart.emblheidelberg.de) database servers. Signal peptide and transmembrane predictions were performed with SignalP4.0 (http://www.cbs.dtu.dk/services/SignalP4.0/) and TMHMM ServerNv2.0 (http://www.cbs.dtu.dk/services/TMHMM/). Subcellular localization and nuclear localization signals (NLS) were predicted with LocTree3 (https://rostlab.org/services/loctree3/) and NLS mapper (http://nls-mapper.iab.keio.ac.jp/cgi-bin/NLS Mapper_form.cgi), respectively. The predicted molecular weights and the isoelectric points were determined by the compute_pi server (http://web.expasy.org/compute pi/). The homology search was repeated 2-3 times to identify all significant matches. Pairwise percentage sequence identity and similarity were calculated using the Matrix Global Alignment Tool (MatGAT) version 2.02 using a BLOSUM50 scoring matrix. Multiple sequence alignment of amino acid sequences belonging to cyclophilins, FKBPs and parvulins were performed using MUSCLE algorithm in Jalview software 2.11.1.3. with default parameters (http://www.jalview.org/ ). Secondary structure features were predicted using Jpred3 server (http:// www.compbio.dundee.ac.uk/www-jpred/). The phylogenetic tree was constructed with the aligned PPlase sequences using the ClustalW algorithm in Mega X software and using the neighbor-joining (NJ) method with default options. For statistical reliability, the bootstrap analysis was conducted with 1000 replicates. The constructed tree files were visualized and finally drawn by Iterative Tree of Life (iTOL). The MEME (http://meme-suite.org/tools/meme ) was used to analyze conserved and potential motifs with the parameter settings of a minimum motif width of 6, a maximum motif width of 150 , and a maximum number of motifs of 15 . Exon-intron organization was predicted using the Gene Structure Display Server 2.0 (GSDS 2.0) (http://gsds.cbi.pku.edu.cn/) by comparing the coding sequences with corresponding DNA sequences.

\section{cDNA synthesis and quantitative Real-time PCR (qRT-PCR):}

The expression of different cyclophilin, FKBP, parvulin and PTPA genes in P. oxalicum was analyzed by the real-time PCR by designing gene-specific primers (Supplementary Table S11). Total RNA from the harvested mycelia was isolated at different stages of growth using a Trizol reagent (Invitrogen, USA) according to the manufacturer's instructions. After removing DNA by DNasel (Sigma-Aldrich) treatment, the RNA was quantified, and its integrity was confirmed by denaturing agarose gel electrophoresis (1.4\%) followed by staining with ethidium bromide. Superscript III First-strand synthesis system kit (Invitrogen) was used to synthesize cDNA from $5 \mu \mathrm{g}$ RNA using Random Hexamer primers according to the manufacturer's instructions. The cDNA products were diluted 10-fold prior to use for real-time PCR. The primers for qRT-PCR were designed using Primer-BLAST ${ }^{82}$ and primer 3 (https://bioinfo.ut.ee/primer30.4.0/). Semi-quantitative reverse transcriptase (RT)-PCR was performed to check the specificity of primers prior to the qRT-PCR. The qRT-PCR was carried out using Ariamx Real-time PCR system with Brillant III ultra-Fast SYBR green QPCR master mix (Agilent Technologies, USA) according to manufacturer's protocol. The $10 \mu \mathrm{l}$ qRT-PCR reaction consisted of $1 X$ SYBR Green QPCR master mix, $60 \mathrm{ng}$ of cDNA and $100 \mathrm{nM}$ forward and reverse primers. The PCR programme comprised of initial incubation at $95^{\circ} \mathrm{C}$ for $10 \mathrm{~min}$, followed by 40 cycles of denaturation at $95^{\circ} \mathrm{C}$ for $10 \mathrm{~s}$; annealing for $15 \mathrm{~s}$ at $60{ }^{\circ} \mathrm{C}$ and $20 \mathrm{~s}$ extension at $72{ }^{\circ} \mathrm{C}$, followed by melt curve analysis to verify the amplification specificity. To check the contamination, dimer formation and presence of genomic DNA, no template and No reverse transcriptase controls were also included. Gene encoding actin (ACTIN) was used as a reference. The Ct values were processed by $2^{-\triangle \triangle C t}$ method to calculate the relative mRNA levels for different genes ${ }^{83}$. All analyses were performed in three biological replicates with three technical replicates. The data obtained were subjected to ANOVA. 


\section{Statistical analysis:}

All the data were presented as mean \pm S.E. All the experiments were performed in triplicate unless otherwise specified. The data were analyzed by two-way analysis of variance (ANOVA) via Tukey's multiple comparison test using Graph pad prism 7 software.

\section{Results}

The halotolerant endophytic fungal strain used in the present study for expression analysis of PPlase genes was identified as $P$. oxalicum. Microscopic observations revealed fungal hyphae to be highly branched with long brush-like branched conidiophores producing phialides with a short narrow neck. Conidia were smooth-walled, cylindrical to ellipsoidal and produced in chains in long parallel columns (Fig. 1a). Though this strain was able to grow in the presence of up to $15 \% \mathrm{NaCl}$, the growth was substantially higher in the medium lacking salt (Fig. $1 \mathrm{~b}$ ) since the colony diameter after ten days of incubation at $30^{\circ} \mathrm{C}$ was higher $(5.1 \mathrm{~cm})$ compared to salt stress $(1.2 \mathrm{~cm})$. Further, relative to the unamended medium, the colonies obtained in the presence of salt were compact and depicted reduced sporulation. The mycelial fresh and dry weights of the culture were affected differently by salt stress. While the fresh weight was higher in the medium lacking salt, the mycelial dry weight was significantly greater in the presence of $\mathrm{NaCl}$ (Fig. 1c), which is in agreement with similar observations reported earlier for other fungi ${ }^{44}$. However, ultrastructure studies and the estimation of compatible solutes are required to understand the mechanism responsible for the salt-induced increase in the mycelial biomass of this strain.

\section{Bioinformatics analysis}

\section{Cyclophilins}

In silico analysis revealed 237 full-length CLD-containing putative cyclophilin proteins in different species of Penicillium (Table 1). The number of cyclophilins in different Penicillium spp. range between $7-11$, with the P. oxalicum genome encoding ten cyclophilins (Supplementary Table S1). Based on homology, the Penicillium cyclophilins were clustered into 12 different orthogroups viz., PenCYP01-PenCYP12 (Table 2, Supplementary Table S2a-I), which was also validated by their phylogenetic clustering (Fig. 2). Genes encoding different cyclophilins of the same orthogroup depicted conservation in their intron-exon architecture (Supplementary Fig. S1). While the genes for PenCYP09 cyclophilins (Group C) showed the absence of introns, the genes of orthogroup PenCYP06 (Group H) depicted up to seven introns (Supplementary Fig. S1). The PenCYP01, PenCYP05, PenCYP06 and PenCYP11 members were observed in all Penicillium spp., suggesting their essential role (Table 2). The PenCYP12 orthogroup comprises of only two cyclophilins, PcoCYP121 (121.93 kDa) and PgrCYP121 (121.9 kDa), that were observed only in P. coprophilum and P. griseofulvum, respectively (Supplementary Table S2I). Variable homology was noticed among cyclophilins of different orthogroups, with the interspecific divergence being higher in the members of PenCYP06 and PenCYP10, that showed a minimum similarity of $51.6 \%$ and $41.3 \%$, respectively (Supplementary Table S3f, j). On the contrary, the orthogroups PenCYP01, PenCYP11 and PenCYP12 demonstrated greater conservation, with the minimum similarity being $90.7 \%, 84.2 \%$ and $97.1 \%$, respectively (Supplementary Table S3a, $\mathrm{k}$, I).

The predicted molecular weights (MWs) and pls of the Penicillium cyclophilins range between $17.63 \mathrm{kDa}(P$. steckii) to $126.82 \mathrm{kDa}(P$. arizonense), and $4.56(P$. expansum) to 9.32 (P. steckii), respectively (Table 1). The cyclophilins in P. oxalicum also showed divergence in their MWs and pls, with the values ranging between 17.79 kDa (PoxCYP17) to 69.82 kDa (PoxCYP69), and 5.93 (PoxCYP41) to 8.87 (PoxCYP18), respectively (Supplementary Table S1). Though predominantly cytosolic, the cyclophilins in Penicillium were also predicted to localize to the nucleus, endoplasmic reticulum (ER) and mitochondria, highlighting functional divergence of these proteins (Table 1; Supplementary Table S2a-I). Besides cytosolic, the ER-localized (PoxCYP23) and nuclear PPlases (PoxCYP54, PoxCYP62-1, PoxCYP62-2 and PoxCYP69) were also observed in P. oxalicum (Supplementary Table S1). Except for PenCYP07 cyclophilins, in which the CLD ranges between 128-179 AAs, this domain's length is similar in cyclophilins of all other orthogroups (Supplementary Table S2a-I). The secondary structure of CLD, comprising of a typical $\beta$-barrel of eight antiparallel $\beta$-sheets with the two ends closed by a-helices and represented as $\beta \square \beta \square \mathrm{a} \square \beta \square \beta \square \beta \square \beta \square \mathrm{a} \square\left[\square \mathrm{a} \square \beta \rrbracket\right.$ in hCYPA (Supplementary Fig. S2) ${ }^{24}$, showed conservation in cyclophilins of all orthogroups except PenCYP03, PenCYP05, PenCYP11 and PenCYP12 which either lack or contain a partial $\beta 1$ region. Based on the presence of domains other than CLD, the cyclophilins were further classified as single domain (SD) or multidomain (MD) proteins (Table 3). While seven orthogroups (PenCYP01-PenCYP06 and PenCYP09) consist of SD cyclophilins, five orthogroups (PenCYP07, PenCYP08, PenCYP10-PenCYP12) comprise of MD proteins that contain additional domains such as TPR, RRM, U-box, WD, PP2C, and GIT_SDH (Supplementary Table S2a-I). Both SD (6) and MD cyclophilins (4) were also observed in P. oxalicum (Supplementary Table S1). This study predicted 15 different motifs within and outside the CLD (Supplementary Fig. S1), the motif composition being conserved in different cyclophilins of the same orthogroup. Comparative analysis with hCYPA revealed that all the active site residues corresponding to Arg (55), Phe (60), Met (61), Gln (63), Ala (101), Phe (113), Trp (121), Leu (122) and His (126), essential for PPlase activity and CsA interaction, are conserved in all cyclophilins of orthogroups PenCYP03, PenCYP06, PenCYP11 and PenCYP12 (Table 4, Supplementary Fig. S2). In P. oxalicum also, the PoxCYP17, PoxCYP18, PoxCYP23 and PoxCYP69 proteins showed retention of all the active site residues (Supplementary Table S4). Thus, these proteins are likely to be enzymatically active and might perform different cellular functions due to their PPlase activity. On the contrary, the cyclophilins belonging to the groups PenCYP02, PenCYP04, PenCYP05 and PenCYP07-PenCYP10 exhibited several substitutions in their active site residues, with the most common being Trp (121)/His (126) replaced with other residues (Table 4, Supplementary Fig. S2). While Trp121 in hCYPA is essential for CsA binding and changes in this residue result in decreased sensitivity to this immunosuppressant, mutations in the other active site residues are known to result in alteration in the PPlase activity ${ }^{45-48}$. The effect of alterations in the active site residues on PPlase activity of these cyclophilins needs further evaluation by cloning and characterizing these proteins.

The phylogenetic relationship among different cyclophilins was studied by constructing an unrooted tree based on proteins consisting of full-length or partial CLD sequences. This analysis divided the Penicillium cyclophilins into 11 distinct groups, A-K (Fig. 2). Interestingly, no $P$. oxalicum cyclophilin was observed in group $\mathrm{G}$, suggesting that this gene might have been acquired by other species or lost from the $P$. oxalicum during the course of evolution. Similar events were implicated earlier in the evolution of plant NAC gene family also ${ }^{49}$. A noteworthy feature of Group K, comprising of PenCYP07 orthogroup, is the presence of PcaCYP7, PexCYP8, PitCYP8, PgrCYP7, and PsoCYP7 (that contain only N-terminus CLD) along with PcaCYP33, PexCYP33, PitCYP33, PgrCYP33 and 
PsoCYP33 (which possess only C-terminus CLD). It is likely that PcaCYP7, PexCYP8, PitCYP8, PgrCYP7 and PsoCYP7 might be the result of deletion of Nterminus region of CLD in PcaCYP33, PexCYP33, PitCYP33, PgrCYP33 and PsoCYP33, respectively. This speculation is supported by the fact that pairwise alignment of PcaCYP7, PexCYP8, PgrCYP7, PitCYP8, and PsoCYP7 with PcaCYP33, PexCYP33, PgrCYP33, PitCYP33, and PsoCYP33, respectively, corresponded to full-length cyclophilins that are homologous to other members of the same group (Supplementary Fig. S3). Though PgrCYP121 and PcoCYP121 were clustered in Group I, pairwise comparison prompted us to designate these proteins as a separate orthogroup PenCYP12 due to the presence of a large stretch of 950 AA residues that was not observed in other members of this group. The two proteins depicted $97 \%$ and $94 \%$ similarity in their GIT_SDH and CLD domains. Interestingly, GIT_SDH domain has not been reported yet in any of the Penicillium cyclophilins.

\section{FK506-binding proteins (FKBPs)}

Ninety-three putative FKBPs were identified in Penicillium spp. by basic local alignment search tool (BLAST) analysis using the human FKBP, hFKBP12, as a query. The hFKBP12 is the smallest member $(12 \mathrm{kDa})$ of the FKBP family and contains the PPlase core domain ${ }^{50,51}$. Based on similarity, these proteins were categorized into four different orthogroups viz., PenFKBP01, PenFKBP02, PenFKBP03 and PenFKBP04 (Table 2). This grouping was also supported by the phylogenetic analysis, which depicted a close relationship of these proteins within a group (Fig. 3a). All Penicillium spp. except $P$. decumbens, $P$. occitanis and $P$. steckii depicted four different FKBPs. While $P$. decumbens contain only two FKBPs, both $P$. occitanis and $P$. steckii consist of three each (Table 2). Interestingly, P. antarcticum exhibited two different PenFKBP02 proteins, PanFKBP12-1 and PanFKBP13, that are $72.1 \%$ similar and appear to be paralogous (Supplementary Table S5b). The presence of PenFKBP02 and PenFKBP03 FKBPs in all Penicillium spp. underlines their essential role in the cell. The number of introns in FKBP genes varies between 1 to 5, with PsuFKBP61 of the orthogroup PenFKBP01 being the only exception with seven introns (Supplementary Fig. S4). Except for PsuFKBP61, the intron-exon architecture showed conservation in the FKBP genes of the same orthogroup. The FKBPs of orthogroup PenFKBP02 showed highest similarity with hFKBP12 (58\%-71.3\%), followed by PenFKBP01 (13.4\%-61.2\%), PenFKBP03 (36.4\%-51.1\%), and PenFKBP04 (14.8\%-16\%) (Supplementary Table S5a-d). Of the different $P$. oxalicum FKBPs, the maximum similarity with hFKBP12 was observed for PoxFKBP12-1 (64.5\%), followed by PoxFKBP12-2 (61.2\%), PoxFKBP14 (51.1\%) and PoxFKBP52 (15.1\%) (Supplementary Table S5e). The similarity among different FKBPs in P. oxalicum ranges between $15.3 \%-73.6 \%$ (Supplementary Table S5e).

Interspecific variability observed in the MWs and pls of FKBPs in each orthogroup in Penicillium suggests divergence (Table 5, Supplementary Table S6a-d). The MWs of FKBPs in P. oxalicum differ from $12.93 \mathrm{kDa}$ to $52.72 \mathrm{kDa}$, with a pl range of 4.38-9.36 (Table S1). The FKBPs in Penicillium spp. were predicted to localize to different subcellular organelles. While members of the orthogroups PenFKBP01 and PenFKBP02 might localize to the cytosol, the PenFKBP03 and PenFKBP04 FKBPs are likely to be present in the ER and nucleus, respectively (Table 3). An ER retention sequence (KDEL) (Supplementary Fig. S5) might be responsible for the likely presence of PenFKBP03 proteins in the ER. Contrary to the PenFKBP01, PenFKBP02 and PenFKBP03 proteins, which consist of only FKBP domain, the PenFKBP04 members also exhibited a nucleoplasmin like (NPL) domain (Table 3). The FKBP domain, consisting of four to six antiparallel beta-sheets surrounding the alpha-helix and represented as $\beta \square \beta \square \beta \square \mathrm{a} \square \beta \square \mathrm{a} \square\left[\square \square \beta \square\right.$ in $\mathrm{hFKBP} 12^{24}$, is conserved in all Penicillium FKBPs except for few members of orthogroup PenFKBP01 that lack the $\beta 1$-sheet (Supplementary Fig. S6). Of the 15 different motifs observed in Penicillium FKBPs, the motifs 1 and 3 , part of the FKBP domain, were observed in all the proteins. (Supplementary Fig. S4). Comparison of the 13 key residues that are implicated in FK506binding $^{52}$ revealed that relative to hFKBP12, the members of orthogroups PenFKBP01, PenFKBP02, PenFKBP03 and PenFKBP04 showed conservation at six, eight, nine and ten positions respectively (Table 4, Supplementary Fig. S6).

\section{Parvulins}

On the basis of homology with human parvulins hPIN1 (Protein Interacting with NIMA) and hPAR14 (human parvulin 14), the Penicillium parvulins were grouped into two different orthogroups viz., PenPIN01 and PenPAR01, respectively (Table 2). Phylogenetic analysis also provided evidence for the evolutionary relationship of these proteins within each orthogroup (Fig. 3b). The genes encoding PenPIN01 (except PsuPIN21) and PenPAR01 showed one and two introns, respectively (Supplementary Fig. S7). Whereas, PenPAR01 proteins were observed in all Penicillium spp. analyzed, the PenPIN01 parvulins were not detected in P. antarcticum, P. arizonense, P. coprophilum and P. solitum (Table 2). The PenPAR01 and PenPIN01 parvulins showed 53.7\%-68.5\%, and 57.7\%-66.7\%, similarity with hPAR14 and hPIN1, respectively (Supplementary Table S7a, b). In P. oxalicum also, the PoxPAR14 and PoxPIN1 shared 66.9\% and 65.7\% similarity with their human orthologues hPAR14 and hPIN1, respectively. High similarity among members of PenPAR01 (65.4-100\%) and PenPIN01 (76.5\%-100\%) groups implies conservation of parvulins among different species of Penicillium (Supplementary Table S7a, b). Except for PdePAR17 (17.67 $\mathrm{kDa}$ ) in P. decumbens, the MWs of PenPAR01 proteins differed between 13.62 to $14.75 \mathrm{kDa}$, and that of PenPIN01 members between 19.30 to $21.88 \mathrm{kDa}$ (Table 6). The pl values in orthogroups PenPAR01 and PenPIN01 varied between 9.41 to 9.68 , and 5.72 to 6.46 , respectively. The larger size of PdePAR17 is attributed to an extended $\mathrm{N}$ terminal 36 amino acid sequence containing mitochondrial localization signal ${ }^{53}$. Except for PdePAR17, which might be a mitochondrial protein, all members of the PenPAR01 orthogroup were predicted to localize to either cytosol or nucleus. Majority of the PenPIN01 proteins, on the contrary, appeared to be nuclear, with only P. steckii (PstPAR13) and P. subrubescens (PsuPAR14) depicting localization in the cytoplasm. Contrary to the PenPAR01 parvulins, that contain only the PPlase domain, the PenPIN01 members also exhibited an additional conserved N-terminal WW domain (Table 3). The PenPAR01 and PenPIN01 parvulins contain ten different motifs, with the motifs 1, 4 and 5 present in all members. (Supplementary Fig. S7). Whereas all the ten active site residues relative to hPIN1 are conserved in PenPIN01 parvulins, only five active site residues in PenPAR02 members showed conservation relative to hPAR14 (Table 4). As observed in hPAR14 and hPIN1 ${ }^{54}$, all Penicillium parvulins exhibited the presence of $\beta 1 \mathrm{a} 1 \mathrm{a} 2 \mathrm{a} 3 \beta 2 \mathrm{a} 4 \beta 3 \beta 4$ elements in their PPlase domain (Supplementary Fig. S8a, b), suggesting that the secondary structure of these proteins is conserved across taxa. Though conservation of these proteins underlines their fundamental role in the cell, the absence of PenPIN01 members in P. antarcticum, P. arizonense, $P$. coprophilum and $P$. solitum also suggests redundancy in their functions.

Protein phosphatase 2A phosphatase activators (PTPAs) 
The members of PenPTPA01 and PenPTPA02 orthogroups in Penicillium spp. were identified by BLAST analysis based on their similarity with their yeast orthologues YPA1 and YPA2, respectively. This analysis revealed that except for $P$. nalgiovense and $P$. steckii, which lack PTPA02 gene, all other Penicillium species contain both the PTPAs (Table 2, 7). Phylogenetic analysis also supported a close evolutionary relationship among proteins of each orthogroup (Fig. 3c). In silico studies further revealed that while all the genes encoding PenPTPA01 proteins contain two introns, the same is lacking in the PenPTPA02 genes (Supplementary Fig. S9). The YPA1 exhibited 44.3\%-49.2\% similarity with PenPTPA01 orthologues, compared to 53.1\%-57.4\% for YPA2 with PenPTPA02 members (Supplementary Table S8a, b). The molecular weights of PenPTPA01 and PenPTPA02 vary between 46.43 to $52.97 \mathrm{kDa}$, and 46.05 to $47.55 \mathrm{kDa}$, respectively, while the pl values for the two PPlases range between 5.81-7.20 and 5.84-6.44, respectively (Table 7). The PenPTPA01 and PenPTPA02 proteins in Penicillium spp. were predicted to localize to the cytosol, and consist of only PTPA domain of 283-331 and 293-295 amino acid residues, respectively. The two PTPA orthogroups revealed the presence of 15 different motifs, of which six (1-3, 6 and 9) are common to all members (Supplementary Fig. S9). High similarity among PenPTPA01 (69.3\%-100\%) and PenPTPA02 (77.1\%-100\%) members in Penicillium spp. suggests conservation, indicating an essential role for these proteins in the cell (Supplementary Table S8a, b).

\section{Estimation of PPlase activity and expression analysis of PPlases genes in P. oxalicum}

The total and specific PPlase activities under salt stress were significantly higher than control at all the stages of growth in $P$. oxalicum (Fig. 4a, b,c). Further, the PPlase activity under control conditions was not regulated temporally since no significant difference in the mycelial catalytic activity was observed at different growth stages. On the contrary, substantial enhancement in the specific PPlase activity was noticed between 4 and 7 days after inoculation (DAl) under salt stress that appeared to be due to induction of PPlases since decrease in total protein content during this duration was $40.3 \%$ (from 9.04 to $5.4 \mathrm{mg} / \mathrm{g}$ fresh weight) compared to $88.7 \%$ (from 8.3 to $15.68 \mathrm{nmol} / \mathrm{sec} / \mathrm{mg}$ protein) increase in specific PPlase activity (Fig. 4c, d). FKBPs and cyclophilins' contribution to PPlase activity in P. oxalicum was evaluated by the extent of inhibition by their specific inhibitors FK506 and CsA, respectively. Whereas PPlase activity under control conditions was almost completely inhibited by CsA at all the growth stages, the CsA-induced inhibition in the presence of salt was about $85 \%$ and $87 \%$ at 4 and 7 DAl, respectively (Fig. 4 e). These observations imply that PPlase activity in the mycelia of $P$. oxalicum was predominantly contributed by the cyclophilins. However, $15 \%$ and $13 \%$ abrogation of PPlase activity by FK506 at 4 and 7 DAl under salt stress also indicated the contribution of FKBPs to enzyme activity at these stages. We carried out real time-PCR analysis to further analyze the contribution of different PPlase genes to the mycelial PPlase activity. This analysis revealed that three cyclophilin (PoxCYP18, PoxCYP23 and PoxCYP41) and two FKBP genes (PoxFKBP12-2 and PoxFKBP52) were expressed at all stages of growth under both control and salt stress conditions (Fig. 5). Whereas the expression of PoxCYP18 at 4 and 10 DAI increased significantly under salt stress, the transcript levels of PoxCYP23, PoxCYP41, PoxFKBP12-2 and PoxFKBP52 at all stages of growth decreased substantially. However, the transcripts corresponding to parvulins and PTPAs were not observed at any of the stages analyzed.

\section{Discussion}

The present study reports in silico characterization of PPlase gene families in Penicillium, and their regulation by salt tress in the mycelia of a halotolerant strain of $P$. oxalicum. This analysis revealed that the number of cyclophilins in Penicillium spp. varies between 7 to 11 (Table 1 ), which is comparable to that reported in other fungi $8,40,55,56$. The cyclophilins in Penicillium spp. were predicted to localize to different cellular compartments. The cytoplasmic cyclophilins PenCYP01 and PenCYP05, the ER-targeted PenCYP06 and the nuclear predicted PenCYP11 were observed in all Penicillium spp. (Table 3), suggesting their indispensable role in the cell. The cyclophilins also play an essential role in mitochondria, with the CPR3 and CyP-D in yeast and humans, respectively, implicated in the regulation of mitochondrial permeability transition pore ${ }^{57-59}$. However, contrary to the widespread prevalence of these proteins in mitochondria of different fungi ${ }^{40}$, our analysis revealed the presence of mitochondrial cyclophilins only in seven species of Penicillium (Table 1 ). The absence of mitochondrial cyclophilins in majority (17) of the Penicillium spp., therefore, needs to be validated by analyzing the CsA-inhibitable PPlase activity in these subcellular organelles.

The occurrence of different functional domains points towards the acquisition of novel roles by these cyclophilins, since domains such as TPR and WD repeats facilitate protein-protein interactions, while RRM and U-box containing proteins have been implicated in RNA stabilization and ubiquitination, respectively ${ }^{60-63}$. The presence of RRM and nuclear localization signal in the cyclophilins of orthogroup PenCYP08 (Table 3) suggests that these proteins may have a role in RNA processing or regulation of transcription ${ }^{64,65}$. A noteworthy feature of this study was that cyclophilins with GIT_SHD2 domain (orthogroup PenCYP12) were observed only in P. coprophilum and P. griseofulvum (Supplementary Table S2I). To our knowledge, the GIT_SHD2 domain has not been reported in cyclophilins of other fungi studied yet. Therefore, this novel combination of domains indicates species-specific neofunctionalization of cyclophilins in Penicillium and warrants in depth investigations to understand their cellular implications.

The FKBP repertoire in Penicillium varies from two in $P$. decumbens to five in $P$. antarcticum (Table 2), which is consistent with similar findings in other fungi ${ }^{40}$. Further, the localization of Penicillium FKBPs to the cytosol, ER and nucleus, and the presence of a single FKBP domain in these proteins (Table 3 ) is also in accordance with the earlier studies ${ }^{40}$. The role of different FKBPs in Penicillium has not been analyzed yet but studies with Schizosaccharomyces pombe demonstrated that though not essential, the SpFKBP12 plays a vital role in the early steps of sexual development pathway ${ }^{66}$. Since SpFKBP12 is orthologous to PenFKBP02 members, the latter may also be performing a similar role in the cell which needs to be confirmed by further experimentation. The ER-localized FKBPs of the orthogroup PenFKBP03 (Table 3) showed a high degree of homology (66.9\%) with human FKBP13 (Supplementary Table S9), a membraneassociated protein localized to the lumen of the $\mathrm{ER}^{67-69}$. As suggested for hFKBP13 ${ }^{70}$, the PenFKBP03 FKBPs may also be involved in protein folding in the ER that is imperative for the survival of the cells and explains the presence of these proteins in all Penicillium spp. On the contrary, the ability of $P$. decumbens, $P$. occitanis and P. steckii to complete growth and development despite lacking either PenFKBP01 or both PenFKBP01 and PenFKBP04 members $(P$. decumbens) (Table 2) indicates redundancy in the functions of these proteins. Owing to the NPL domain (Table 3), the PenFKBP04 Group FKBPs in Penicillium might be involved in nucleosome assembly and regulation of gene expression, as demonstrated for the NPL containing yeast FKBP, Fpr4 ${ }^{71,72}$, with 
which these proteins show considerable similarity (52.5\%-56.4\%) (Supplementary Table S10). The existence of NPL domain suggests the acquisition of novel roles by these proteins that may be enabling the cells to respond to different developmental and environmental cues.

Parvulins have been implicated in post-phosphorylation control of diverse cellular processes such as cell division, gene expression, immune response, etc. ${ }^{73-}$

75. The identification of parvulins in Penicillium with and without WW domain (Table 3) supports the earlier findings in E. coli, yeast and Arabidopsis ${ }^{8,76}$. Though the N-terminal WW domain in PIN1-type parvulins facilitates specific binding to phosphorylated Thr/Ser-Pro motifs and their subsequent cis-trans isomerization by the C-terminal PPlase domain ${ }^{77}$, the PIN1-type PPlases in Arabidopsis and Malus domestica plants, despite lacking this domain, exhibited no difference in substrate specificity ${ }^{78}$. Therefore, further studies are required to understand the significance of the WW domain in regulating the parvulin activities in Penicillium.

The occurrence of genes encoding PenPTPA01 and PenPTPA02 in all Penicillium spp., except $P$. nalgiovense and $P$. steckii that lack the PenPTPA02 proteins (Table 2), signifies their indispensable role in the cell. These proteins may be involved in the activation of PP2A-like phosphatases, as reported for their yeast orthologues YPA1 and YPA2 ${ }^{6}$. Though information about the active site residues required for PPlase activity in PTPAs is elusive, deletion of a conserved domain 208-GVWGLD-213 in YPA1 resulted in about 400-fold attenuation of phosphotyrosyl phosphatase activation reaction of PP2A ${ }^{6}$. Since the same amino acid stretch is also present in the PenPTPA01 and PenPTPA02 members in all Penicillium spp. (Supplementary Fig. 10), these proteins may likely have PPlase activity. Cloning and characterization of these proteins are, nevertheless, required to validate this speculation.

\section{Analysis of PPlase activity and expression of PPlase genes}

Biochemical investigations revealed significantly higher PPlase activity under salt stress in the halotolerant $P$. oxalicum, which was predominantly inhibited by CsA, underscoring the contribution of cyclophilins (Fig. 4a-e). Of the three cyclophilins (PoxCYP18, PoxCYP23 and PoxCYP41) and two FKBP genes (PoxFKBP12-2 and PoXFKBP52) expressed in the mycelia, the salt-induced increase was observed only for PoxCYP18 (Fig. 5), implying its contribution to the mycelial PPlase activity. Though the maximum increase in transcript levels of PoxCYP18 was observed at 4 DAl, the PPlase activity was highest at 10 DAl. It is likely that this gene may be regulated at the post-transcriptional level and/or the expressed protein is highly stable and gets accumulated with time, thereby, leading to enhanced activity at later stages of growth. Estimation of the PPlase proteins by immunoblotting is, nonetheless, required to understanding the molecular basis of this observation. Since protection by cyclophilins and FKBPs against stress-induced damage to the cell is attributed to their PPlase activity and/or chaperone functions ${ }^{79}$, further biochemical characterization of these proteins in Penicillium is imperative to elucidate their precise mechanism of action. Although expression of other PPlases was not observed at the stages studied, their role in specific developmental processes and adaptation to other stresses cannot be ruled out as previous studies have demonstrated the role of these genes in the regulation of several developmental process ${ }^{79}$. Further studies on the expression of PPlase genes at different developmental stages are required to enhance our understanding of the role of these genes in halotolerance of $P$. oxalicum.

\section{Conclusions}

To conclude, this study has shown that the number of genes encoding PPlases varies between 7-11, 2-5, 1-2 and 1-2 for cyclophilins, FKBPs, parvulins and PTPAs, respectively, in different species of Penicillium. Though cyclophilins, FKBPs and parvulins have been characterized earlier in several fungal species, this is the first study to characterize all the PPlases in Penicillium spp. Despite conservation of the secondary structure of the CLD and FKBP domains, the cyclophilins and FKBPs in Penicillium spp. have undergone divergence by the acquisition of novel domains such as PP2C and GIT_SDH, implying neofunctionalization. In addition to the cytoplasm, the localization of PPlases in Penicillium to other subcellular compartments viz., ER, mitochondria and nucleus, suggests their specific roles. This study further demonstrated that the mycelial PPlase activity in a halotolerant strain of $P$. oxalicum is induced significantly under salt stress and is primarily contributed by the cyclophilins, signifying the role of these genes in stress response.

\section{Declarations}

\section{Acknowledgements}

Financial support from the Council of Scientific and Industrial Research, Government of India, for carrying out this research work is gratefully acknowledged. Kirandeep Kaur is thankful to University Grants Commission, Govt. of India for the award of Rajiv Gandhi National Fellowship.

\section{References}

1. Brandts, J. F., Halvorson, H. R. \& Brennan, M. Consideration of the possibility that the slow step in protein denaturation reactions is due to cis-trans isomerism of proline residues. Biochemistry 14, 4953-4963 (1975).

2. Schulz, G. E. \& Schirmer, R. H. Principles of protein structure. Springer Science \& Business Media (1979).

3. Fischer, G., Wittmann-Liebold, B., Lang, K., Kiefhaber, T. \& Schmid, F. X. Cyclophilin and peptidyl-prolyl cis-trans isomerase are probably identical proteins. Nature 337, 476-478 (1989).

4. Rahfeld, J. U., Schierhorn, A., Mann, K. \& Fischer, G. A novel peptidyl-prolyl cis-trans isomerase from Escherichia coli. FEBS Lett. 343, 65-69 (1994).

5. Adams, B., Musiyenko, A., Kumar, R. \& Barik, S. A novel class of dual-family immunophilins. J. Biol. Chem. 280, 24308-24314 (2005).

6. Jordens, J. et al. The protein phosphatase 2A phosphatase activator is a novel peptidyl-prolyl cis-trans isomerase. J. Biol. Chem. 281, 6349-6357 (2006).

7. Kumari, S., Roy, S., Singh, P., Singla-Pareek, S. L. \& Pareek, A. Cyclophilins: Proteins in search of function. Plant Signaling and Behavior 8, 25-32 (2013).

8. Arevalo-Rodriguez, M., Wu, X., Hanes, S. D. \& Heitman, J. Prolyl isomerases in yeast. Frontiers in bioscience9, 2420-2446 (2004).

Page $7 / 22$ 
9. Galat, A. Function-dependent clustering of orthologues and paralogues of cyclophilins. Proteins Struct. Funct. Genet. 56, 808-820 (2004).

10. Nigro, P., Pompilio, G. \& Capogrossi, M. C. Cyclophilin A: A key player for human disease. Cell Death and Disease 4, e888-e888 (2013).

11. Hanhart, P. et al. Bioinformatic and expression analysis of the Brassica napus L. Cyclophilins. Sci. Rep. 7, 1-17 (2017).

12. Singh, H., Kaur, K., Singh, S., Kaur, P. \& Singh, P. Genome-wide analysis of cyclophilin gene family in wheat and identification of heat stress responsive members. Plant Gene 19, 100197 (2019).

13. Dolinski, K., Muir, S., Cardenas, M. \& Heitman, J. All cyclophilins and FK506-binding proteins are, individually and collectively, dispensable for viability in Saccharomyces cerevisiae. Proc. Natl. Acad. Sci. U. S. A. 94, 13093-13098 (1997).

14. Ghartey-Kwansah, G. et al. Comparative analysis of FKBP family protein: Evaluation, structure, and function in mammals and Drosophila melanogaster. BMC Dev. Biol. 18, 1-12 (2018).

15. Gollan, P. J. \& Bhave, M. Genome-wide analysis of genes encoding FK506-binding proteins in rice. Plant Mol. Biol. 72, 1-16 (2010).

16. Lu, K. P., Hanes, S. D. \& Hunter, T. A human peptidyl-prolyl isomerase essential for regulation of mitosis. Nature 380, 544-547 (1996).

17. Uchida, T., Fujimori, F., Tradler, T., Fischer, G. \& Rahfeld, J. U. Identification and characterization of a 14 kDa human protein as a novel parvulin-like peptidyl-prolyl cis-trans isomerase. FEBS Lett. 446, 278-282 (1999).

18. Mueller, J. W. et al. Characterization of novel elongated parvulin isoforms that are ubiquitously expressed in human tissues and originate from alternative transcription initiation. BMC Mol. Biol. 7, (2006).

19. Magnusdottir, A. et al. The crystal structure of a human PP2A phosphatase activator reveals a novel fold and highly conserved cleft implicated in proteinprotein interactions. J. Biol. Chem. 281, 22434-22438 (2006).

20. Sykes, K., Gething, M. J. \& Sambrook, J. Proline isomerases function during heat shock. Proc. Natl. Acad. Sci. U. S. A. 90, 5853-5857 (1993).

21. Chen, A. P. et al. Ectopic expression of ThCYP1, a stress-responsive cyclophilin gene from Thellungiella halophila, confers salt tolerance in fission yeast and tobacco cells. Plant Cell Rep. 26, 237-245 (2007).

22. Kumari, S., Singh, P., Singla-Pareek, S. L. \& Pareek, A. Heterologous expression of a salinity and developmentally regulated rice cyclophilin gene (OsCyp2) in E. coli and S. cerevisiae confers tolerance towards multiple abiotic stresses. Mol. Biotechnol. 42, 195-204 (2009).

23. Kumari, S. et al. Expression of a cyclophilin OsCyp2-P isolated from a salt-tolerant landrace of rice in tobacco alleviates stress via ion homeostasis and limiting ROS accumulation. Funct. Integr. Genomics 15, 395-412 (2015).

24. Vasudevan, D. et al. Plant immunophilins: A review of their structure-function relationship. Biochimica et Biophysica Acta-General Subjects 10, 21452158 (2015)

25. Kaur, G. et al. The peptidyl-prolyl cis-trans isomerase activity of the wheat cyclophilin, TaCypA-1, is essential for inducing thermotolerance in Escherichia coli. Biochim. 2, 9-15 (2016).

26. Kaur, G. et al. Role of cysteine residues in regulation of peptidyl-prolyl cis-trans isomerase activity of wheat cyclophilin TaCYPA-1. Protein Pept. Lett. 24, (2017).

27. Kurek, I., Aviezer, K., Erel, N., Herman, E. \& Breiman, A. The wheat peptidyl-prolyl cis-trans isomerase FKBP77 is heat induced and developmentally regulated. Plant Physiol. 119, 693-703 (1999).

28. Luan, S., Kudla, J., Gruissem, W. \& Schreiber, S. L. Molecular characterization of a FKBP-type immunophilin from higher plants. Proc. Natl. Acad. Sci. U. S. A. 93, 6964-6969 (1996).

29. Subin, C. S., Pradeep, M. A. \& Vijayan, K. K. FKBP-type peptidyl-prolyl cis-trans isomerase from thermophilic microalga, Scenedesmus sp.: molecular characterisation and demonstration of acquired salinity and thermotolerance in E. coli by recombinant expression. J. Appl. Phycol. 28, 3307-3315 (2016).

30. Hamlyn, P. F., Wales, D. S. \& Sagar, B. F. Extracellular enzymes of Penicillium. (1987).

31. Kozlovskii, A. G., Zhelifonova, V. P. \& Antipova, T. V. Fungi of the genus Penicillium as producers of physiologically active compounds (Review). Applied Biochemistry and Microbiology 49, 1-10 (2013).

32. Visagie, C. M. et al. Identification and nomenclature of the genus Penicillium. Stud. Mycol. 78, 343-371 (2014).

33. Serra, I. et al. Seawater-Based Biocatalytic Strategy: Stereoselective reductions of ketones with marine yeasts. ChemCatChem 8, 3254-3260 (2016).

34. Turk, M. et al. Salt-induced changes in lipid composition and membrane fluidity of halophilic yeast-like melanized fungi. Extremophiles 8, 53-61 (2004).

35. Gunde-Cimerman, N., Ramos, J. \& Plemenitaš, A. Halotolerant and halophilic fungi. Mycological Research 113, 1231-1241 (2009).

36. Hohmann, S. Osmotic adaptation in yeast-control of the yeast osmolyte system. Int. Rev. Cytol. 215, 149-187 (2002).

37. Vaupotic, T. \& Plemenitas, A. Osmoadaptation-dependent activity of microsomal HMG-CoA reductase in the extremely halotolerant black yeast Hortaea werneckii is regulated by ubiquitination. FEBS Lett. 581, 3391-3395 (2007).

38. Lindquist, S. Heat-shock proteins and stress tolerance in microorganisms. Curr. Opin. Genet. Dev. 2, 748-755 (1992).

39. Wang, W., Vinocur, B., Shoseyov, O. \& Altman, A. Role of plant heat-shock proteins and molecular chaperones in the abiotic stress response. Trends Plant Sci. 9, 244-252 (2004).

40. Pemberton, T. J. Identification and comparative analysis of sixteen fungal peptidyl-prolyl cis-trans isomerase repertoires. BMC Genomics 7, (2006).

41. Joseph, J. D., Heitman, J. \& Means, A. R. Molecular cloning and characterization of Aspergillus nidulans cyclophilin B. Fungal Genet. Biol. 27, 55-66 (1999).

42. Derkx, P. M. F. \& Madrid, S. M. The Aspergillus niger cypA gene encodes a cyclophilin that mediates sensitivity to the immunosuppressant cyclosporin A. Mol. Genet. Genomics 266, 527-536 (2001). 
43. Holliday, M. J. et al. Structure and dynamics of GeoCyp: A thermophilic cyclophilin with a novel substrate binding mechanism that functions efficiently at low temperatures. Biochemistry 54, 3207-3217 (2015).

44. Beever, R. E. \& Laracy, E. P. Osmotic adjustment in the filamentous fungus Aspergillus nidulans. J. Bacteriol. 168, 1358-1365 (1986).

45. Liu, J. et al. Calcineurin is a common target of cyclophilin-cyclosporin A and FKBP-FK506 complexes. Cel/ 66, 807-815 (1991).

46. Zydowsky, L. D. et al. Active site mutants of human cyclophilin A separate peptidyl-prolyl isomerase activity from cyclosporin A binding and calcineurin inhibition. Protein Sci. 1, 1092-1099 (1992).

47. Hoffmann, K., Kakalis, L. T., Anderson, K. S., Armitage, I. M. \& Handschumacher, R. E. Expression of human cyclophilin-40 and the effect of the His141 $\rightarrow$ Trp mutation on catalysis and cyclosporin A binding. Eur. J. Biochem. 229, 188-193 (1995).

48. Davis, T. L. et al. Structural and biochemical characterization of the human cyclophilin family of peptidyl-prolyl isomerases. PLoS Biol. 8, 1000439 (2010). 49. Hu, R. et al. Comprehensive Analysis of NAC domain transcription factor gene family in Populus trichocarpa. BMC Plant Biol. 10, 1-23 (2010).

50. Harding, M. W., Galat, A., Uehling, D. E. \& Schreiber, S. L. A receptor for the immuno-suppressant FK506 is a cis-trans peptidyl-prolyl isomerase. Nature 341, 758-760 (1989).

51. Siekierka, J. J., Hung, S. H. Y., Poe, M., Lin, C. S. \& Sigal, N. H. A cytosolic binding protein for the immunosuppressant FK506 has peptidyl-prolyl isomerase activity but is distinct from cyclophilin. Nature 341, 755-757 (1989).

52. Fanghänel, J. \& Fischer, G. Insights into the catalytic mechanism of peptidyl-prolyl cis-trans isomerases. Frontiers in bioscience 9 , 3453-3478 (2004).

53. Kessler, D. et al. The DNA binding parvulin Par17 is targeted to the mitochondrial matrix by a recently evolved prepeptide uniquely present in Hominidae. BMC Biol. 1, 1-14 (2007)

54. Matena, A., Rehic, E., Hönig, D., Kamba, B. \& Bayer, P. Structure and function of the human parvulins Pin1 and Par14/17. Biological Chemistry 399, 101125 (2018).

55. Pemberton, T. J. \& Kay, J. E. The cyclophilin repertoire of the fission yeast Schizosaccharomyces pombe. Yeast 22, 927-945 (2005).

56. Mo, C. et al. Genome-wide identification and characterization of the cyclophilin gene family in the nematophagous fungus Purpureocillium lilacinum. Int. J. Mol. Sci. 20, 2978 (2019).

57. Hunter, D. R. \& Haworth, R. A. The $\mathrm{Ca}^{2+}$ induced membrane transition in mitochondria. III. Transitional Ca ${ }^{2+}$ release. Arch. Biochem. Biophys. 195, $468-477$ (1979)

58. Schinzel, A. C. et al. Cyclophilin D is a component of mitochondrial permeability transition and mediates neuronal cell death after focal cerebral ischemia. Proc. Natl. Acad. Sci. U. S. A. 102, 12005-12010 (2005).

59. Halestrap, A. P. Calcium, mitochondria and reperfusion injury: A pore way to die. in Biochemical Society Transactions 34, 232-237 (2006).

60. Lamb, J. R., Tugendreich, S. \& Hieter, P. Tetratrico peptide repeat interactions: to TPR or not to TPR? Trends Biochem. Sci. 20, 257-259 (1995).

61. Neer, E. J., Schmidt, C. J., Nambudripad, R. \& Smith, T. F. The ancient regulatory-protein family of WD-repeat proteins. Nature 371, 297-300 (1994).

62. Krzywicka, A. et al. KIN241: A gene involved in cell morphogenesis in Paramecium tetraurelia reveals a novel protein family of cyclophilin-RNA interacting proteins (CRIPs) conserved from fission yeast to man. Mol. Microbiol. 42, 257-267 (2001).

63. Aravind, L. \& Koonin, E. V. The U box is a modified RING finger-A common domain in ubiquitination. Current Biology 10, 132-134 (2000).

64. Gullerova, M., Barta, A. \& Lorković, Z. J. AtCyp59 is a multidomain cyclophilin from Arabidopsis thaliana that interacts with SR proteins and the C-terminal domain of the RNA polymerase II. Rna 12, 631-643 (2006).

65. Bannikova, O. et al. Identification of RNA targets for the nuclear multidomain cyclophilin atCyp59 and their effect on PPlase activity. Nucleic Acids Res. 41, 1783-1796 (2012).

66. Weisman, R., Finkelstein, S. \& Choder, M. Rapamycin blocks sexual development in fission yeast through inhibition of the cellular function of an FKBP12 homolog. J. Biol. Chem. 276, 24736-24742 (2001).

67. Nigam, S. K. et al. Localization of the FK506-binding protein, FKBP 13, to the lumen of the endoplasmic reticulum. Biochem. J. 294, 511-515 (1993).

68. Bush, K. T., Hendrickson, B. A. \& Nigam, S. K. Induction of the FK506-binding protein, FKBP13, under conditions which misfold proteins in the endoplasmic reticulum. Biochem. J. 303, 705-708 (1994).

69. Jin, Y. et al. Molecular cloning of a membrane-associated human FK506 and rapamycin-binding protein , FKBP-13. Proceedings of the National Academy of Sciences $88,6677-6681$ (1991).

70. Walensky, L. D. et al. The 13-kD FK506-binding protein, FKBP13, interacts with a novel homologue of the erythrocyte membrane cytoskeletal protein 4.1. J. Cell Biol. 141, 143-153 (1998).

71. Xiao, H., Jackson, V. \& Lei, M. The FK506-binding protein, Fpr4, is an acidic histone chaperone. FEBS Lett. 580, 4357-4364 (2006).

72. Nelson, C. J., Santos-Rosa, H. \& Kouzarides, T. Proline isomerization of histone H3 regulates lysine methylation and gene expression. Cel/ 126, $905-916$ (2006).

73. Crenshaw, D. G., Yang, J., Means, A. R. \& Kornbluth, S. The mitotic peptidyl-prolyl isomerase, Pin1, interacts with Cdc25 and PIx1. EMBO J. 17, $1315-1327$ (1998).

74. Eckert, B., Martin, A., Balbach, J. \& Schmid, F. X. Prolyl isomerization as a molecular timer in phage infection. Nat. Struct. Mol. Biol. 12, 619-623 (2005).

75. Yeh, E. S. \& Means, A. R. PIN1, the cell cycle and cancer. Nature Reviews Cancer 7, 381-388 (2007).

76. He, Z., Li, L. \& Luan, S. Immunophilins and parvulins. Superfamily of peptidyl-prolyl isomerases in Arabidopsis. Plant Physiol. 134, 1248-1267 (2004). 
77. Yaffe, M. B. et al. Sequence-specific and phosphorylation dependent proline isomerization: A potential mitotic regulatory mechanism. Science 278, 19571960 (1997).

78. Landrieu, I., Wieruszeski, J. M., Wintjens, R., Inzé, D. \& Lippens, G. Solution structure of the single-domain prolyl cis-trans isomerase PIN1At from Arabidopsis thaliana. J. Mol. Biol. 320, 321-332 (2002).

79. Singh, H., Kaur, K., Singh, M., Kaur, G. \& Singh, P. Plant cyclophilins: Multifaceted proteins with versatile roles. Front. Plant Sci. 11, (2020).

80. Bradford, M. M. A rapid and sensitive method for the quantitation of microgram quantities of protein utilizing the principle of protein-dye binding. Anal. Biochem. 72, 248-254 (1976).

81. Fischer, G., Bang, H., Berger, E. \& Schellenberger, A. Conformational specificity of chymotrypsin toward proline-containing substrates. Biochim. Biophys. Acta (BBA)/Protein Struct. Mol. 791, 87-97 (1984).

82. Ye, J. et al. Primer-BLAST: a tool to design target-specific primers for polymerase chain reaction. BMC Bioinformatics 13, 134 (2012).

83. Livak, K. J. \& Schmittgen, T. D. Analysis of relative gene expression data using real-time quantitative PCR and the $2^{-\triangle \Delta C T}$ method. Methods 25 , $402-408$ (2001).

\section{Tables}

Table 1: Genome-wide analysis of cyclophilin proteins in different Penicillium spp.

\begin{tabular}{|c|c|c|c|c|c|c|c|c|c|}
\hline S. No. & Penicillium spp. & Genes & Proteins & AA residues & MW (kDa) & pl & SD & MD & $\begin{array}{l}\text { Subcellular } \\
\text { localization }\end{array}$ \\
\hline 1 & P. antarcticum & 09 & 09 & $162-627$ & $17.76-69.22$ & $5.59-8.26$ & 05 & 04 & C, ER, N \\
\hline 2 & P. arizonense & 10 & 10 & $162-1183$ & $17.77-126.82$ & $5.32-8.70$ & 06 & 04 & C, ER, N \\
\hline 3 & P. brasilianumn & 10 & 10 & $162-657$ & $17.85-72.46$ & $5.28-8.93$ & 06 & 04 & C, ER, N \\
\hline 4 & P. camemberti & 10 & 10 & $73-627$ & $17.73-69.56$ & $5.5-8.450$ & 07 & 03 & C, ER, N \\
\hline 5 & P. chrysogenum & 10 & 10 & $162-627$ & $17.70-69.51$ & $5.76-8.59$ & 07 & 03 & C, ER, N \\
\hline 6 & P. coprophilum & 08 & 08 & $162-1110$ & $17.77-121.93$ & $5.78-8.61$ & 05 & 03 & C, ER, N \\
\hline 7 & P. decumbens & 07 & 07 & $159-629$ & $17.76-69.56$ & $5.93-9.13$ & 06 & 01 & C, ER, M, N \\
\hline 8 & P. digitatum & 11 & 11 & $162-627$ & $17.67-69.60$ & $4.68-8.60$ & 07 & 04 & C, ER, N \\
\hline 9 & P. expansum & 10 & 10 & $73-627$ & $17.72-69.48$ & $4.56-8.91$ & 07 & 03 & C, ER, N \\
\hline 10 & P. flavigenum & 09 & 09 & $162-627$ & $17.71-69.48$ & $5.49-9.14$ & 06 & 03 & $\mathrm{C}, \mathrm{ER}, \mathrm{M}, \mathrm{N}$ \\
\hline 11 & P. freii & 11 & 11 & $162-627$ & $17.70-69.52$ & $5.42-8.96$ & 07 & 04 & $\mathrm{C}, \mathrm{ER}, \mathrm{M}, \mathrm{N}$ \\
\hline 12 & P. griseofulvum & 10 & 10 & 73-1108 & $17.74-121.89$ & $5.68-8.63$ & 06 & 04 & C, ER, N \\
\hline 13 & P. italicum & 10 & 10 & $73-627$ & $17.70-69.55$ & $4.66-8.40$ & 07 & 03 & C, ER, N \\
\hline 14 & P. nalgiovense & 11 & 11 & $162-627$ & $17.68-69.61$ & $4.63-8.96$ & 07 & 04 & $C, E R, M, N$ \\
\hline 15 & P. nordicum & 11 & 11 & $162-627$ & $17.90-69.30$ & $5.42-8.96$ & 07 & 04 & $C, E R, M, N$ \\
\hline 16 & P. occitanis & 10 & 10 & $162-631$ & $17.69-70.39$ & $4.72-8.63$ & 06 & 04 & C, ER, N \\
\hline 17 & P. oxalicum & 10 & 10 & $162-627$ & $17.79-69.82$ & $5.93-8.87$ & 06 & 04 & C, ER, N \\
\hline 18 & P. polonicum & 08 & 08 & $162-627$ & $17.69-69.49$ & $5.54-7.93$ & 06 & 02 & C, ER, N \\
\hline 19 & P. roqueforti & 11 & 11 & $162-627$ & $17.74-69.41$ & $5.65-8.89$ & 07 & 04 & C, ER, N \\
\hline 20 & P. rubens & 11 & 11 & $162-627$ & $17.70-69.51$ & $5.76-8.59$ & 07 & 04 & C, ER, N \\
\hline 21 & P. solitum & 10 & 10 & $73-627$ & $17.72-69.52$ & $5.49-8.45$ & 07 & 03 & $C, E R, N$ \\
\hline 22 & P. steckii & 11 & 11 & $161-629$ & $17.63-69.81$ & $5.73-9.32$ & 07 & 04 & $C, E R, M, N$ \\
\hline 23 & P. subrubescens & 10 & 10 & $162-629$ & $17.87-69.57$ & $5.48-8.89$ & 06 & 04 & $\mathrm{C}, \mathrm{ER}, \mathrm{N}$ \\
\hline 24 & P. vulpinum & 09 & 09 & $162-627$ & $17.76-69.47$ & $5.76-8.95$ & 06 & 03 & $C, E R, M, N$ \\
\hline
\end{tabular}

Table 2: Representation of cyclophilin, FK506-binding protein (FKBP), parvulin, and protein phosphatase 2A activator (PTPA) orthogroups in different Penicillium spp. 


\begin{tabular}{|c|c|c|c|c|c|c|c|c|c|c|c|}
\hline & & Cyclophilins & & & & & & & & & \\
\hline $\begin{array}{l}\text { S. } \\
\text { No. }\end{array}$ & $\begin{array}{l}\text { Penicillium } \\
\text { spp. }\end{array}$ & Cyclophilins & PenCYP01 & PenCYP02 & PenCYP03 & PenCYP04 & PenCYP05 & PenCYP06 & PenCYP07 & PenCYP08 & Pen \\
\hline 1 & $\begin{array}{l}P . \\
\text { antarcticum }\end{array}$ & 9 & $P$ & 0 & $P$ & 0 & $P$ & $P$ & $P$ & $P$ & $P$ \\
\hline 2 & P. arizonense & 10 & $P$ & 0 & $P$ & $P$ & $P$ & $P$ & $P$ & $P$ & $P$ \\
\hline 3 & $\begin{array}{l}\text { P. } \\
\text { brasilianumn }\end{array}$ & 10 & $P$ & $P$ & $P$ & 0 & $P$ & $P$ & $P$ & $P$ & $P$ \\
\hline 4 & $\begin{array}{l}\text { P. } \\
\text { camemberti }\end{array}$ & 10 & $P$ & $P$ & $P$ & $P$ & $P$ & $P$ & 0 & $P$ & $P$ \\
\hline 5 & $\begin{array}{l}P . \\
\text { chrysogenum }\end{array}$ & 10 & $\mathrm{P}$ & $P$ & $P$ & $\mathrm{P}$ & $P$ & $\mathrm{P}$ & 0 & $P$ & $P$ \\
\hline 6 & $\begin{array}{l}\text { P. } \\
\text { coprophilum }\end{array}$ & 8 & $P$ & $P$ & 0 & $P$ & $P$ & $P$ & 0 & 0 & 0 \\
\hline 7 & P. decumbens & 7 & $P$ & $P$ & $P$ & $P$ & $P$ & $P$ & 0 & 0 & 0 \\
\hline 8 & P. digitatum & 11 & $\mathrm{P}$ & $\mathrm{P}$ & $\mathrm{P}$ & $P$ & $P$ & $P$ & $P$ & $\mathrm{P}$ & $P$ \\
\hline 9 & P. expansum & 10 & $\mathrm{P}$ & $P$ & $P$ & $P$ & $P$ & $P$ & 0 & $P$ & $P$ \\
\hline 10 & P. flavigenum & 9 & $P$ & $P$ & $P$ & $P$ & $P$ & $P$ & 0 & $P$ & 0 \\
\hline 11 & P. freii & 11 & $P$ & $P$ & $P$ & $P$ & $P$ & $P$ & $P$ & $P$ & $P$ \\
\hline 12 & $\begin{array}{l}P . \\
\text { griseofulvum }\end{array}$ & 10 & $P$ & $P$ & 0 & $P$ & $P$ & $P$ & 0 & $P$ & $P$ \\
\hline 13 & P. italicum & 10 & $P$ & $P$ & $P$ & $P$ & $P$ & $P$ & 0 & $P$ & $P$ \\
\hline 14 & $\begin{array}{l}P . \\
\text { nalgiovense }\end{array}$ & 11 & $P$ & $P$ & $P$ & $P$ & $P$ & $P$ & $P$ & $P$ & $P$ \\
\hline 15 & P. nordicum & 11 & $\mathrm{P}$ & $P$ & $P$ & $P$ & $P$ & $P$ & $P$ & $P$ & $P$ \\
\hline 16 & P. occitanis & 10 & $P$ & $P$ & $P$ & 0 & $P$ & $P$ & $P$ & $P$ & $P$ \\
\hline 17 & P. oxalicum & 10 & $P$ & $P$ & $P$ & 0 & $P$ & $P$ & $P$ & $P$ & $P$ \\
\hline 18 & P. polonicum & 8 & $P$ & $P$ & 0 & $P$ & $P$ & $\mathrm{P}$ & 0 & 0 & $P$ \\
\hline 19 & P. roqueforti & 11 & $P$ & $P$ & $P$ & $P$ & $P$ & $P$ & $P$ & $P$ & $P$ \\
\hline 20 & P. rubens & 11 & $P$ & $P$ & $P$ & $P$ & $P$ & $P$ & $P$ & $P$ & $P$ \\
\hline 21 & P. solitum & 10 & $P$ & $P$ & $P$ & $P$ & $P$ & $P$ & 0 & $P$ & $P$ \\
\hline 22 & P. steckii & 11 & $\mathrm{P}$ & $P$ & $P$ & $P$ & $P$ & $P$ & $P$ & $P$ & $P$ \\
\hline 23 & $\begin{array}{l}\text { P. } \\
\text { subrubescens }\end{array}$ & 10 & $P$ & $P$ & $P$ & 0 & $P$ & $P$ & $P$ & $P$ & $P$ \\
\hline 24 & P. vulpinum & 9 & $P$ & $P$ & $P$ & $P$ & $P$ & $P$ & 0 & $P$ & 0 \\
\hline
\end{tabular}

Table 3: Domain architecture and localization of different orthogroups of cyclophilins, FK506-binding proteins (FKBPs), parvulins and protein phosphatase 2A activators (PTPAs) in Penicillium spp. 


\begin{tabular}{|c|c|c|c|c|c|c|}
\hline & Orthogroups & Proteins & SD & MD & Domains & Localization \\
\hline \multirow[t]{13}{*}{ Cyclophilins } & PenCYP01 & 24 & 24 & 0 & CLD (24) & C \\
\hline & PenCYP02 & 22 & 22 & 0 & CLD (22) & C \\
\hline & PenCYP03 & 21 & 21 & 0 & CLD (21) & C (14), M (7) \\
\hline & PenCYP04 & 19 & 19 & 0 & CLD (19) & C \\
\hline & PenCYP05 & 24 & 24 & 0 & CLD (24) & $\mathrm{C}$ \\
\hline & PenCYP06 & 24 & 24 & 0 & CLD (24) & ER \\
\hline & PenCYP07 & 13 & 0 & 13 & CLD+TPR (13) & $\mathrm{C}$ \\
\hline & PenCYP08 & 21 & 0 & 21 & CLD+RRM (21) & $\mathrm{N}$ \\
\hline & PenCYP09 & 20 & 20 & 0 & CLD (20) & $\mathrm{N}$ \\
\hline & \multirow[t]{2}{*}{ PenCYP10 } & \multirow[t]{2}{*}{23} & \multirow[t]{2}{*}{0} & \multirow[t]{2}{*}{23} & CLD+U-box (22) & \multirow[t]{2}{*}{$\mathrm{N}$} \\
\hline & & & & & CLD+U-box + PP2C (1) & \\
\hline & PenCYP11 & 24 & 0 & 24 & CLD+WD REPEAT (24) & $\mathrm{N}$ \\
\hline & PenCYP12 & 2 & 0 & 2 & CLD+GIT_SDH (2) & C \\
\hline \multirow[t]{4}{*}{ FKBPs } & PenFKBP01 & 21 & 21 & 0 & FKBP (21) & C \\
\hline & PenFKBP02 & 25 & 25 & 0 & FKBP (21) & C \\
\hline & PenFKBP03 & 24 & 24 & 0 & FKBP (21) & ER \\
\hline & PenFKBP04 & 23 & 0 & 23 & FKBP+NPL (23) & $\mathrm{N}$ \\
\hline \multirow[t]{2}{*}{ PARs } & PenPAR01 & 24 & 24 & 0 & PPlase (24) & C (14), M (1), N (9) \\
\hline & PenPIN01 & 20 & 0 & 20 & PPlase+WW (20) & C (2), N (18) \\
\hline \multirow[t]{2}{*}{ PTPAs } & PenPTPA01 & 24 & 24 & 0 & PTPA (24) & $\mathrm{C}$ \\
\hline & PenPTPA02 & 22 & 22 & 0 & PTPA (22) & $\mathrm{C}$ \\
\hline
\end{tabular}

Table 4: Conservation of the active site residues, with respect to the human orthologues hCYPA, hFKBP12 and hPIN1/hPAR14, respectively, in the cyclophilins, FK506-binding proteins (FKBPs) and parvulins of different orthogroups in different Penicillium spp.

\begin{tabular}{|c|c|c|c|c|c|c|c|c|c|c|}
\hline \multicolumn{11}{|l|}{ Cyclophilins } \\
\hline \multirow[t]{3}{*}{ Orthogroups } & Conserved & ARG & PHE & MET & GLN & ALA & PHE & TRP & LEU & HIS \\
\hline & ASRs & (R) & $(F)$ & (M) & (Q) & (A) & $(F)$ & (W) & (L) & $(\mathrm{H})$ \\
\hline & & 55 & 60 & 61 & 63 & 101 & 113 & 121 & 122 & 126 \\
\hline PenCYP01 & 8 & $\mathrm{R}$ & $\mathrm{F}$ & M & $\mathrm{Q}$ & A & $F / Y$ & W & L & $\mathrm{H}$ \\
\hline PenCYP02 & 8 & $\mathrm{R}$ & $\mathrm{F}$ & $M$ & $\mathrm{Q}$ & $A$ & $\mathrm{~F}$ & $\mathrm{~F}$ & $L$ & $\mathrm{H}$ \\
\hline PenCYP03 & 9 & $\mathrm{R}$ & $\mathrm{F}$ & M & Q & A & $\mathrm{F}$ & W & $\mathrm{L}$ & $\mathrm{H}$ \\
\hline PenCYP04 & 8 & $\mathrm{R}$ & $\mathrm{F}$ & $M$ & $\mathrm{Q}$ & A & $F$ & $\mathrm{H}$ & L & $\mathrm{H}$ \\
\hline PenCYP05 & 7 & $\mathrm{R}$ & $\mathrm{F}$ & $M$ & Q & A & $F$ & $\mathrm{H}$ & L & $S$ \\
\hline PenCYP06 & 9 & $\mathrm{R}$ & $\mathrm{F}$ & M & $\mathrm{Q}$ & A & $\mathrm{F}$ & W & L & $\mathrm{H}$ \\
\hline PenCYP07 & 8 & $\mathrm{R}$ & $\mathrm{F}$ & M & Q & A & $\mathrm{F}$ & $\mathrm{H}$ & $\mathrm{L}$ & $\mathrm{H}$ \\
\hline PenCYP08 & 5 & $\mathrm{R}$ & $\mathrm{F}$ & $\mathrm{T} / \mathrm{S}$ & $\mathrm{Q}$ & A & $\mathrm{I} / \mathrm{L}$ & Y & L & A \\
\hline PenCYP09 & 5 & $\mathrm{R}$ & $\mathrm{F}$ & V & $\mathrm{Q}$ & A & $F$ & $\mathrm{R}$ & L/M & C \\
\hline PenCYP10 & 8 & $\mathrm{R}$ & $\mathrm{F}$ & $M$ & Q & A & $F$ & $\mathrm{H}$ & L & $\mathrm{H}$ \\
\hline PenCYP11 & 9 & $\mathrm{R}$ & $\mathrm{F}$ & M & $\mathrm{Q}$ & A & $\mathrm{F}$ & W & $L$ & $\mathrm{H}$ \\
\hline PenCYP12 & 9 & $\mathrm{R}$ & $\mathrm{F}$ & $M$ & $\mathrm{Q}$ & $A$ & $\mathrm{~F}$ & W & L & $\mathrm{H}$ \\
\hline
\end{tabular}




\begin{tabular}{|c|c|c|c|c|c|c|c|c|c|c|c|c|c|c|}
\hline \multicolumn{15}{|l|}{ FKBPs } \\
\hline \multirow[t]{3}{*}{ Orthogroups } & Conserved & TYR & PHE & ASP & ARG & PHE & PHE & Gln (Q) 54 & GLU & ILE & TRP & TYR & HIS & PHE \\
\hline & ASRs & $(Y)$ & $(F)$ & (D) & (R) & $(F)$ & $(F)$ & & (E) & (l) & $(W)$ & $(Y)$ & $(H)$ & $(F)$ \\
\hline & & 27 & 37 & 38 & 43 & 47 & 49 & & 55 & 57 & 60 & 83 & 88 & 100 \\
\hline PenFKBP01 & 6 & $Y$ & $\mathrm{~F}$ & $\mathrm{D}$ & $\mathrm{P}$ & $\mathrm{F} / \mathrm{L}$ & V & G & $\mathrm{K} / \mathrm{Q}$ & $1 /-$ & W & $\mathrm{Y}$ & - & $\mathrm{F}$ \\
\hline PenFKBP02 & 8 & $\mathrm{Y}$ & $\mathrm{F}$ & $\mathrm{D}$ & $\mathrm{R}$ & $\mathrm{F} / \mathrm{L}$ & $\mathrm{S} / \mathrm{T}$ & G & $\mathrm{R}$ & 1 & W & $\mathrm{Y}$ & $F / Y$ & $\mathrm{~F}$ \\
\hline PenFKBP03 & 9 & $\mathrm{Y}$ & $\mathrm{F}$ & $\mathrm{D}$ & $\mathrm{R}$ & $\mathrm{L}$ & $\mathrm{F}$ & G & $\mathrm{R}$ & 1 & W & $\mathrm{Y}$ & $\mathrm{I} / \mathrm{V} / \mathrm{M}$ & $\mathrm{F}$ \\
\hline PenFKBP04 & 10 & $\mathrm{Y}$ & $\mathrm{F}$ & D & $\mathrm{K}$ & $\mathrm{F}$ & $\mathrm{F}$ & G & E & 1 & W & $Y$ & $\mathrm{~L}$ & $\mathrm{~F}$ \\
\hline
\end{tabular}

\begin{tabular}{|c|c|c|c|c|c|c|c|c|c|c|c|}
\hline \multicolumn{12}{|l|}{ Parvulins } \\
\hline \multirow[t]{3}{*}{ Parvulins } & Conserved & HIS & LYS & ARG & ARG & CYS (C)/ & LEU & MET & PHE & SER (S)/ & HIS \\
\hline & ASRs & $(\mathrm{H})$ & (K) & (R) & (R) & ASP (D)* & (L) & (M) & $(F)$ & PHE (F)* & $(\mathrm{H})$ \\
\hline & & 59 & 63 & 68 & 69 & 113 & 122 & 130 & 134 & 154 & 157 \\
\hline PenPAR01(vs hPAR14) & 5 & $\mathrm{H}$ & $\#$ & $\#$ & $\#$ & $\mathrm{D}$ & L & L & $\mathrm{F}$ & $\mathrm{F} / \mathrm{H}$ & $\mathrm{H}$ \\
\hline PenPIN01 (vs hPIN1) & 10 & $\mathrm{H}$ & $\mathrm{K}$ & $\mathrm{R}$ & $\mathrm{R}$ & $\mathrm{C}$ & L & M & $\mathrm{F}$ & S & $\mathrm{H}$ \\
\hline
\end{tabular}

Table 5: Genome-wide analysis of FK506-binding proteins (FKBPs) in different Penicillium spp. 


\begin{tabular}{|c|c|c|c|c|c|c|c|c|c|}
\hline S. No. & Penicillium spp. & Genes & Proteins & AA residues & MW (kDa) & $\mathrm{pl}$ & SD & MD & $\begin{array}{l}\text { Subcellular } \\
\text { localization }\end{array}$ \\
\hline 1 & P. antarcticum & 05 & 05 & $115-478$ & $12.33-51.91$ & $4.34-9.36$ & 04 & 01 & $\mathrm{C}, \mathrm{ER}, \mathrm{N}$ \\
\hline 2 & P. arizonense & 04 & 04 & $121-479$ & $12.89-52.05$ & $4.34-9.36$ & 03 & 01 & $C, E R, N$ \\
\hline 3 & P. brasilianumn & 04 & 04 & $121-478$ & $12.87-51.85$ & $4.35-9.36$ & 03 & 01 & C, ER, N \\
\hline 4 & P. camemberti & 04 & 04 & $121-487$ & $12.92-53.24$ & $4.40-9.36$ & 03 & 01 & $C, E R, N$ \\
\hline 5 & P. chrysogenum & 04 & 04 & $121-488$ & $12.90-53.24$ & $4.38-9.36$ & 03 & 01 & C, ER, N \\
\hline 6 & P. coprophilum & 04 & 04 & $122-487$ & $12.88-53.22$ & $4.39-9.52$ & 03 & 01 & C, ER, N \\
\hline 7 & P. decumbens & 02 & 02 & $122-130$ & $13.09-14.15$ & $5.59-6.72$ & 02 & 00 & C, ER \\
\hline 8 & P. digitatum & 04 & 04 & $121-497$ & $12.98-54.37$ & $4.49-9.36$ & 03 & 01 & C, ER, N \\
\hline 9 & P. expansum & 04 & 04 & $121-494$ & $12.95-54.12$ & $4.44-9.36$ & 03 & 01 & $C, E R, N$ \\
\hline 10 & P. flavigenum & 04 & 04 & $121-486$ & $12.90-53.04$ & $4.37-9.36$ & 03 & 01 & C, ER, N \\
\hline 11 & P. freii & 04 & 04 & $109-489$ & $11.53-53.43$ & $4.42-9.43$ & 03 & 01 & C, ER, N \\
\hline 12 & P. griseofulvum & 04 & 04 & $121-491$ & $12.90-53.56$ & 4.33-9.52 & 03 & 01 & C, ER, N \\
\hline 13 & P. italicum & 04 & 04 & $121-483$ & $12.98-52.83$ & $4.83-9.36$ & 03 & 01 & C, ER, N \\
\hline 14 & P. nalgiovense & 04 & 04 & $121-489$ & $12.87-53.25$ & 4.35-9.36 & 03 & 01 & C, ER, N \\
\hline 15 & P. nordicum & 04 & 04 & $121-491$ & $12.95-53.58$ & $4.43-9.36$ & 03 & 01 & C, ER, N \\
\hline 16 & P. occitanis & 03 & 03 & $119-478$ & $12.77-52.10$ & $4.33-6.57$ & 02 & 01 & C, ER, N \\
\hline 17 & P. oxalicum & 04 & 04 & $121-484$ & $12.93-52.72$ & $4.38-9.36$ & 03 & 01 & $\mathrm{C}, \mathrm{ER}, \mathrm{N}$ \\
\hline 18 & P. polonicum & 04 & 04 & $121-489$ & $12.92-53.44$ & $4.42-9.36$ & 03 & 01 & C, ER, N \\
\hline 19 & P. roqueforti & 04 & 04 & $121-475$ & $12.89-51.70$ & $4.43-9.36$ & 03 & 01 & C, ER, N \\
\hline 20 & P. rubens & 04 & 04 & $121-488$ & $12.90-53.24$ & $4.38-9.36$ & 03 & 01 & C, ER, N \\
\hline 21 & P. solitum & 04 & 04 & $121-492$ & $12.92-53.85$ & $4.40-9.36$ & 03 & 01 & C, ER, N \\
\hline 22 & P. steckii & 03 & 03 & $123-475$ & $13.17-51.56$ & 4.31-7.09 & 02 & 01 & C, ER, N \\
\hline 23 & P. subrubescens & 04 & 04 & $121-553$ & $12.87-61.22$ & $4.36-6.06$ & 02 & 02 & $\mathrm{C}, \mathrm{ER}, \mathrm{N}$ \\
\hline 24 & P. vulpinum & 04 & 04 & $121-491$ & $12.89-53.64$ & $4.43-9.40$ & 03 & 01 & $\mathrm{C}, \mathrm{ER}, \mathrm{N}$ \\
\hline
\end{tabular}

Table 6: Genome-wide analysis of parvulins in different species of Penicillium. 


\begin{tabular}{|c|c|c|c|c|c|c|c|c|c|c|c|c|}
\hline \multirow[b]{2}{*}{$\begin{array}{l}\text { S. } \\
\text { No. }\end{array}$} & \multirow[b]{2}{*}{$\begin{array}{l}\text { Penicillium } \\
\text { spp. }\end{array}$} & \multicolumn{6}{|c|}{ Orthogroup PenPAR01 } & \multicolumn{5}{|c|}{ Orthogroup PenPIN01 } \\
\hline & & $\begin{array}{l}\text { Protein } \\
\text { name }\end{array}$ & $\begin{array}{l}\text { Protein } \\
\text { accession no. }\end{array}$ & $\begin{array}{l}\text { Total AAs/ } \\
\text { (Rotamase } \\
\text { domain) }\end{array}$ & $\begin{array}{l}\mathrm{MW} \\
(\mathrm{kD})\end{array}$ & pl & Loc & $\begin{array}{l}\text { Protein } \\
\text { name }\end{array}$ & $\begin{array}{l}\text { Protein } \\
\text { accession no. }\end{array}$ & $\begin{array}{l}\text { Total } \\
\text { AAs/ } \\
\text { (WW } \\
\text { domain)/ } \\
\text { (PPlase } \\
\text { domain) }\end{array}$ & $\begin{array}{l}\mathrm{MW} \\
(\mathrm{kDa})\end{array}$ & pl \\
\hline 1 & $\begin{array}{l}P . \\
\text { antarcticum }\end{array}$ & PanPAR13 & OQD87118.1 & $\begin{array}{l}127 /(35- \\
127)\end{array}$ & 13.62 & 9.52 & $\mathrm{~N}$ & - & - & - & - & - \\
\hline 2 & P. arizonense & ParPAR13 & XP_022493562.1 & $\begin{array}{l}127 /(35- \\
127)\end{array}$ & 13.64 & 9.52 & C & - & - & - & - & - \\
\hline 3 & $\begin{array}{l}P . \\
\text { brasilianumn }\end{array}$ & PbrPAR14 & CEJ54268.1 & $\begin{array}{l}130 /(38- \\
130)\end{array}$ & 14.17 & 9.45 & $\mathrm{~N}$ & PbrPIN19 & CEJ61044.1 & $\begin{array}{l}176 /(5- \\
38) /(67- \\
175)\end{array}$ & 19.44 & 6.1 \\
\hline 4 & $\begin{array}{l}\text { P. } \\
\text { camemberti }\end{array}$ & PcaPAR13 & CRL17938.1 & $\begin{array}{l}129 /(37- \\
129)\end{array}$ & 13.85 & 9.49 & C & PcaPIN19 & CRL25274. 1 & $\begin{array}{l}176 /(5- \\
38) /(67- \\
175)\end{array}$ & 19.58 & $5 . ;$ \\
\hline 5 & $\begin{array}{l}P \\
\text { chrysogenum }\end{array}$ & PchPAR13 & KZN91971.1 & $\begin{array}{l}129 /(37- \\
129)\end{array}$ & 13.80 & 9.49 & $\mathrm{~N}$ & PchPIN19 & KZN92659.1 & $\begin{array}{l}176 /(5- \\
38) /(67- \\
175)\end{array}$ & 19.55 & $5 . \varepsilon$ \\
\hline 6 & $\begin{array}{l}\text { P. } \\
\text { coprophilum }\end{array}$ & PcoPAR13 & OQE46467.1 & $\begin{array}{l}129 /(37- \\
129)\end{array}$ & 13.74 & 9.49 & C & - & - & - & - & - \\
\hline 7 & P. decumbens & PdePAR17 & OQD75108.1 & $\begin{array}{l}129 /(70- \\
162)\end{array}$ & 17.67 & 9.68 & M & PdePIN19 & OQD67334.1 & $\begin{array}{l}176 /(5- \\
38) /(67- \\
175)\end{array}$ & 19.52 & $6 . \dot{0}$ \\
\hline 8 & P. digitatum & PdiPAR13 & XP_014531496.1 & $\begin{array}{l}129 /(37- \\
129)\end{array}$ & 13.79 & 9.49 & $\mathrm{C}$ & PdiPIN19 & XP_014532624.1 & $\begin{array}{l}176 /(5- \\
38) /(67- \\
175)\end{array}$ & 19.56 & 5.7 \\
\hline 9 & P. expansum & PexPAR13 & XP_016601110.1 & $\begin{array}{l}129 /(37- \\
129)\end{array}$ & 13.79 & 9.49 & $\mathrm{C}$ & PexPIN19 & XP_016603179.1 & $\begin{array}{l}176 /(5- \\
38) /(67- \\
175)\end{array}$ & 19.62 & 5.7 \\
\hline 10 & P. flavigenum & PflPAR13 & OQE30197.1 & $\begin{array}{l}129 /(37- \\
129)\end{array}$ & 13.79 & 9.49 & $\mathrm{C}$ & PflPIN19 & OQE19709.1 & $\begin{array}{l}176 /(5- \\
38) /(67- \\
175)\end{array}$ & 19.55 & $5 . \varepsilon$ \\
\hline 11 & P. freii & PfrPAR13 & KUM64167.1 & $\begin{array}{l}128 /(36- \\
128)\end{array}$ & 13.66 & 9.52 & $\mathrm{C}$ & PfrPIN19 & KUM58880.1 & $\begin{array}{l}176 /(5- \\
38) /(67- \\
175)\end{array}$ & 19.60 & $5 . ;$ \\
\hline 12 & $\begin{array}{l}P . \\
\text { griseofulvum }\end{array}$ & PgrPAR13 & KXG47026.1 & $\begin{array}{l}129 /(37- \\
129)\end{array}$ & 13.79 & 9.49 & $\mathrm{C}$ & PgrPIN20 & KXG54614.1 & $\begin{array}{l}181 /(5- \\
38) /(68- \\
175)\end{array}$ & 20.13 & $5 . €$ \\
\hline 13 & P. italicum & PitPAR13 & KG071764.1 & $\begin{array}{l}129 /(37- \\
129)\end{array}$ & 13.79 & 9.49 & $\mathrm{C}$ & PitPIN19 & KG073822.1 & $\begin{array}{l}176 /(5- \\
38) /(67- \\
175)\end{array}$ & 19.52 & $5 . i$ \\
\hline 14 & $\begin{array}{l}P . \\
\text { nalgiovense }\end{array}$ & PnaPAR13 & OQE86291.1 & $\begin{array}{l}129 /(37- \\
129)\end{array}$ & 13.77 & 9.49 & $\mathrm{~N}$ & PnaPIN19 & OQE93697.1 & $\begin{array}{l}174 /(5- \\
38) /(67- \\
174)\end{array}$ & 19.30 & $5 . \varepsilon$ \\
\hline 15 & P. nordicum & PnoPAR13 & KOS48877.1 & $\begin{array}{l}128 /(36- \\
128)\end{array}$ & 13.67 & 9.52 & C & PnoPIN19 & KOS38539.1 & $\begin{array}{l}176 /(5- \\
38) /(67- \\
175)\end{array}$ & 19.56 & $5 . ;$ \\
\hline 16 & P. occitanis & PocPAR14 & PCH00892.1 & $\begin{array}{l}133 /(37- \\
133)\end{array}$ & 14.75 & 9.48 & $\mathrm{~N}$ & PocPIN21 & PCH00362.1 & $\begin{array}{l}194 /(6- \\
39) /(67- \\
174)\end{array}$ & 21.88 & 6.4 \\
\hline 17 & P. oxalicum & PoxPAR14 & EPS27836.1 & $\begin{array}{l}128 /(36- \\
128)\end{array}$ & 14.00 & 9.57 & $\mathrm{~N}$ & PoxPIN19 & EPS29250.1 & $\begin{array}{l}175 /(5- \\
38) /(67- \\
174)\end{array}$ & 19.43 & $5 . \varsigma$ \\
\hline 18 & P. polonicum & PpoPAR13 & OQD72015.1 & $\begin{array}{l}128 /(36- \\
128)\end{array}$ & 13.66 & 9.52 & $\mathrm{C}$ & PpoPIN19 & OQD71617.1 & $\begin{array}{l}176 /(5- \\
38) /(67- \\
175)\end{array}$ & 19.59 & $5 . ;$ \\
\hline 19 & P. roqueforti & ProPAR13 & CDM33780.1 & $\begin{array}{l}129 /(37- \\
129)\end{array}$ & 13.79 & 9.49 & $\mathrm{C}$ & ProPIN19 & CDM27042.1 & $\begin{array}{l}176 /(5- \\
38) /(67- \\
175)\end{array}$ & 19.59 & $5 . i$ \\
\hline 20 & P. rubens & PruPAR13 & XP_002562081.1 & $\begin{array}{l}129 /(37- \\
129)\end{array}$ & 13.80 & 9.49 & $\mathrm{~N}$ & PruPIN19 & KAF3031078.1 & $\begin{array}{l}176 /(5- \\
38) /(67- \\
175)\end{array}$ & 19.55 & $5 . \varepsilon$ \\
\hline
\end{tabular}




\begin{tabular}{|c|c|c|c|c|c|c|c|c|c|c|c|c|}
\hline 21 & P. solitum & PsoPAR13 & OQD86406.1 & $\begin{array}{l}129 /(37- \\
129)\end{array}$ & 13.77 & 9.41 & C & - & - & - & - & - \\
\hline 22 & P. steckii & PstPAR13 & OQE27721.1 & $\begin{array}{l}128 /(36- \\
128)\end{array}$ & 13.77 & 9.49 & $\mathrm{~N}$ & PstPIN21 & OQE20301.1 & $\begin{array}{l}196 / \\
(26-59) / \\
(88-195)\end{array}$ & 21.82 & $5 . \subseteq$ \\
\hline 23 & $\begin{array}{l}\text { P. } \\
\text { subrubescens }\end{array}$ & PsuPAR14 & OK093703.1 & $\begin{array}{l}129 / \text { / (37- } \\
129)\end{array}$ & 14.17 & 9.57 & $\mathrm{~N}$ & PsuPIN21 & OKP10946.1 & $\begin{array}{l}194 / \\
(10-43) / \\
(72-181)\end{array}$ & 21.40 & 6.2 \\
\hline 24 & P. vulpinum & PvuPAR13 & OQE10874.1 & $\begin{array}{l}129 /(37- \\
129)\end{array}$ & 13.79 & 9.49 & $\mathrm{C}$ & PvuPIN19 & OQE02824.1 & $\begin{array}{l}177 /(5- \\
38) /(68- \\
176)\end{array}$ & 19.61 & $5 . c$ \\
\hline
\end{tabular}

AA: amino acids; C: cytoplasm; kDa: kilodalton; Loc: localization; M: mitochondria; MW: molecular weight; N: nucleus; pl: isoelectric point; WW: Domain with 2 conserved tryptophan residues.

Table 7: Genome-wide analysis of protein phosphatase 2A activators (PTPAs) in different species of Penicillium. 


\begin{tabular}{|c|c|c|c|c|c|c|c|c|c|c|c|c|}
\hline \multirow[b]{2}{*}{$\begin{array}{l}\text { S. } \\
\text { No. }\end{array}$} & \multirow[b]{2}{*}{$\begin{array}{l}\text { Penicillium } \\
\text { spp. }\end{array}$} & \multicolumn{6}{|c|}{ Orthogroup PenPTPA01 } & \multicolumn{5}{|c|}{ Orthogroup PenPTPA02 } \\
\hline & & $\begin{array}{l}\text { Protein } \\
\text { name }\end{array}$ & $\begin{array}{l}\text { Protein } \\
\text { accession no. }\end{array}$ & $\begin{array}{l}\text { Total } \\
\text { AAs / } \\
\text { (PTPA } \\
\text { domain) }\end{array}$ & $\begin{array}{l}\text { MW } \\
(\mathrm{kDa})\end{array}$ & pl & Loc & $\begin{array}{l}\text { Protein } \\
\text { name }\end{array}$ & $\begin{array}{l}\text { Protein } \\
\text { accession no. }\end{array}$ & $\begin{array}{l}\text { Total } \\
\text { AAs / } \\
\text { (PTPA } \\
\text { domain) }\end{array}$ & $\begin{array}{l}\mathrm{MW} \\
(\mathrm{kDa})\end{array}$ & pl \\
\hline 1 & $\begin{array}{l}P . \\
\text { antarcticum }\end{array}$ & PanPTPA52 & OQD82836.1 & $\begin{array}{l}484 / \\
(25-356)\end{array}$ & 52.43 & 6.43 & C & PanPTPA46 & OQD82187.1 & $\begin{array}{l}415 / \\
(54-347)\end{array}$ & 46.05 & 6. \\
\hline 2 & P. arizonense & ParPTPA52 & XP_022485488.1 & $\begin{array}{l}484 / \\
(25-356)\end{array}$ & 52.33 & 6.38 & C & ParPTPA46 & XP_022491893.1 & $\begin{array}{l}415 / \\
(54-349)\end{array}$ & 46.13 & 6. \\
\hline 3 & $\begin{array}{l}P \\
\text { brasilianumn }\end{array}$ & PbrPTPA51 & OOQ86678.1 & $\begin{array}{l}480 / \\
(25-356)\end{array}$ & 51.87 & 5.97 & C & PbrPTPA46 & OOQ83450.1 & $\begin{array}{l}421 / \\
(59-354)\end{array}$ & 46.79 & 6. \\
\hline 4 & $\begin{array}{l}P . \\
\text { camemberti }\end{array}$ & PcaPTPA52 & CRL24247.1 & $\begin{array}{l}485 / \\
(22-352)\end{array}$ & 52.54 & 6.22 & C & PcaPTPA46 & CRL22781.1 & $\begin{array}{l}419 / \\
(58-353)\end{array}$ & 46.37 & 6. \\
\hline 5 & $\begin{array}{l}\text { P. } \\
\text { chrysogenum }\end{array}$ & PchPTPA52 & KZN85308.1 & $\begin{array}{l}487 / \\
(24-354)\end{array}$ & 52.96 & 6.85 & C & PchPTPA46 & KZN84036.1 & $\begin{array}{l}419 / \\
(58-353)\end{array}$ & 46.30 & 6. \\
\hline 6 & $\begin{array}{l}\text { P. } \\
\text { coprophilum }\end{array}$ & PcoPTPA51 & OQE46369.1 & $\begin{array}{l}476 / \\
(24-354)\end{array}$ & 51.84 & 6.61 & C & PcoPTPA46 & OQE41359.1 & $\begin{array}{l}420 / \\
(59-354)\end{array}$ & 46.54 & 6. \\
\hline 7 & P. decumbens & PdePTPA51 & OQD67240.1 & $\begin{array}{l}473 / \\
(25-356)\end{array}$ & 51.20 & 5.81 & C & PdePTPA46 & OQD78624 & $\begin{array}{l}415 / \\
(57-351)\end{array}$ & 46.03 & 6. \\
\hline 8 & P. digitatum & PdiPTPA51 & XP_014532126.1 & $\begin{array}{l}474 / \\
(22-352)\end{array}$ & 51.49 & 7.20 & C & PdiPTPA46 & XP_014536235.1 & $\begin{array}{l}419 / \\
(58-353)\end{array}$ & 46.34 & 6. \\
\hline 9 & P. expansum & PexPTPA52 & XP_016598742.1 & $\begin{array}{l}485 / \\
(22-352)\end{array}$ & 52.82 & 6.85 & C & PexPTPA46 & XP_016596123.1 & $\begin{array}{l}419 / \\
(58-353)\end{array}$ & 46.31 & 6. \\
\hline 10 & P. flavigenum & PflPTPA52 & OQE29046.1 & $\begin{array}{l}487 / \\
(24-354)\end{array}$ & 52.90 & 6.43 & C & PfIPTPA46 & OQE18147.1 & $\begin{array}{l}419 / \\
(58-353)\end{array}$ & 46.26 & 6. \\
\hline 11 & P. freii & PfrPTPA52 & KUM61112.1 & $\begin{array}{l}485 / \\
(22-352)\end{array}$ & 52.80 & 7.10 & C & PfrPTPA46 & KUM59294.1 & $\begin{array}{l}419 / \\
(58-353)\end{array}$ & 46.39 & 6. \\
\hline 12 & $\begin{array}{l}\text { P. } \\
\text { griseofulvum }\end{array}$ & PgrPTPA52 & KXG48326.1 & $\begin{array}{l}487 / \\
(24-354)\end{array}$ & 52.78 & 6.38 & C & PgrPTPA46 & KXG49099.1 & $\begin{array}{l}419 / \\
(58-353)\end{array}$ & 46.30 & 6. \\
\hline 13 & P. italicum & PitPTPA52 & KG074783.1 & $\begin{array}{l}485 / \\
(22-352)\end{array}$ & 52.97 & 6.85 & C & PitPTPA46 & KG075264.1 & $\begin{array}{l}419 / \\
(58-353)\end{array}$ & 46.46 & 6. \\
\hline 14 & $\begin{array}{l}P . \\
\text { nalgiovense }\end{array}$ & PnaPTPA52 & OQE84955.1 & $\begin{array}{l}488 / \\
(24-354)\end{array}$ & 52.93 & 6.61 & C & - & - & - & - & - \\
\hline 15 & P. nordicum & $\begin{array}{l}\text { PnoPTPA46- } \\
1\end{array}$ & KOS46416.1 & $\begin{array}{l}431 / \\
(15-298)\end{array}$ & 46.43 & 6.33 & C & $\begin{array}{l}\text { PnoPTPA46- } \\
2\end{array}$ & KOS43152.1 & $\begin{array}{l}419 / \\
(58-353)\end{array}$ & 46.60 & 6. \\
\hline 16 & P. occitanis & PocPTPA49 & PCH02323.1 & $\begin{array}{l}449 / \\
(19-350)\end{array}$ & 49.74 & 6.08 & C & PocPTPA47 & PCG91093.1 & $\begin{array}{l}424 / \\
(61-354)\end{array}$ & 47.55 & 5. \\
\hline 17 & P. oxalicum & PoxPTPA51 & EPS34045.1 & $\begin{array}{l}478 / \\
(25-356)\end{array}$ & 51.78 & 5.97 & C & PoxPTPA46 & EPS25240.1 & $\begin{array}{l}422 / \\
(60-355)\end{array}$ & 46.80 & 5. \\
\hline 18 & P. polonicum & РpoPTPA52 & OQD61354.1 & $\begin{array}{l}485 / \\
(22-352)\end{array}$ & 52.68 & 6.28 & $\mathrm{C}$ & РpoРTPA46 & OQD61354.1 & $\begin{array}{l}419 / \\
(58-353)\end{array}$ & 46.35 & 6. \\
\hline 19 & P. roqueforti & ProPTPA52 & CDM34519.1 & $\begin{array}{l}482 / \\
(23-353)\end{array}$ & 52.40 & 6.19 & C & ProPTPA46 & CDM28648.1 & $\begin{array}{l}417 / \\
(58-353)\end{array}$ & 46.14 & 6. \\
\hline 20 & P. rubens & PruPTPA52 & XP_002557947.1 & $\begin{array}{l}487 / \\
(24-354)\end{array}$ & 52.96 & 6.85 & C & PruPTPA46 & XP_002559612.1 & $\begin{array}{l}419 / \\
(58-353)\end{array}$ & 46.30 & 6. \\
\hline 21 & P. solitum & PsoPTPA52 & OQE03232.1 & $\begin{array}{l}485 / \\
(22-352)\end{array}$ & 52.76 & 6.23 & C & PsoPTPA46 & OQD95247.1 & $\begin{array}{l}419 / \\
(22-352)\end{array}$ & 46.38 & 6. \\
\hline 22 & P. steckii & PstPTPA52 & OQE16418.1 & $\begin{array}{l}483 / \\
(25-356)\end{array}$ & 52.62 & 5.87 & $\mathrm{C}$ & - & - & - & - & - \\
\hline 23 & $\begin{array}{l}\text { P. } \\
\text { subrubescens }\end{array}$ & PsuPTPA51 & ОКР02397.1 & $\begin{array}{l}479 / \\
(25-356)\end{array}$ & 51.86 & 6.34 & C & PsuPTPA47 & OKР06461.1 & $\begin{array}{l}420 / \\
(58-353)\end{array}$ & 47.00 & 6. \\
\hline 24 & P. vulpinum & PvuPTPA52 & OQE05701.1 & $\begin{array}{l}485 / \\
(24-354)\end{array}$ & 52.88 & 6.33 & $\mathrm{C}$ & PvuPTPA46 & OQE00347.1 & $\begin{array}{l}419 / \\
(58-353)\end{array}$ & 46.48 & 6. \\
\hline
\end{tabular}

\section{Figures}


(a)

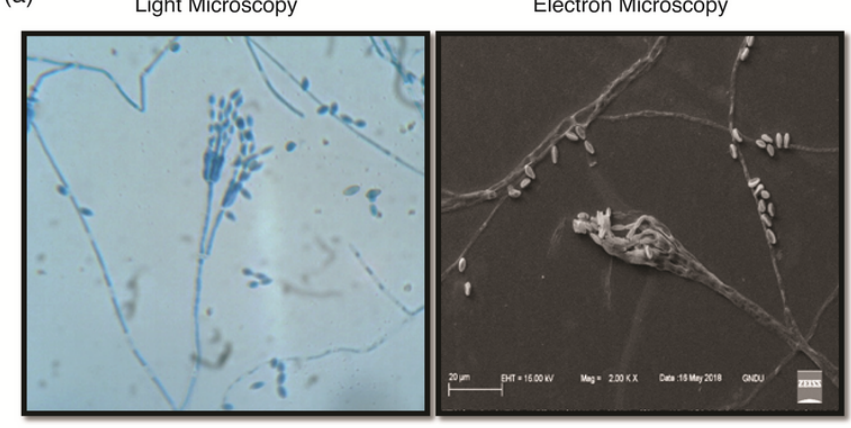

(b)

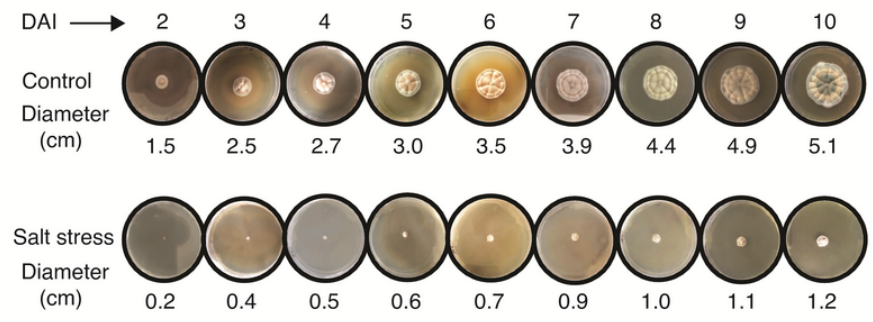

(c)

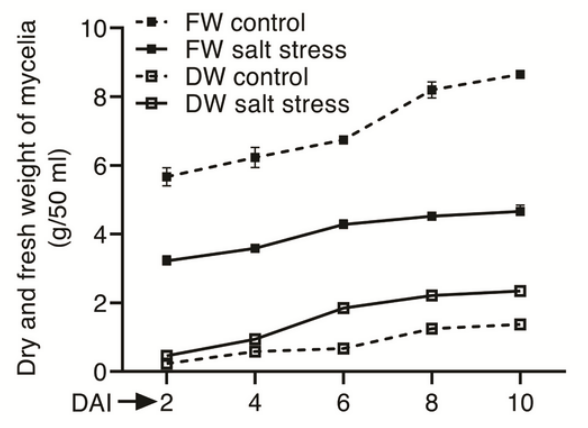

\section{Figure 1}

(a) Light and electron microscopic observations of Penicillium oxalicum fungal hyphae. (b) Growth pattern of P. oxalicum on solid medium in the presence (lower lane) or absence (upper lane) of salt stress $(15 \% \mathrm{NaCl})$. (c) Effect of salt stress $(15 \% \mathrm{NaCl})$ on fresh and dry weights of mycelia at different growth stages in P. oxalicum. The values depict the mean of three biological replicates \pm standard error. (DAl: days after inoculation). 


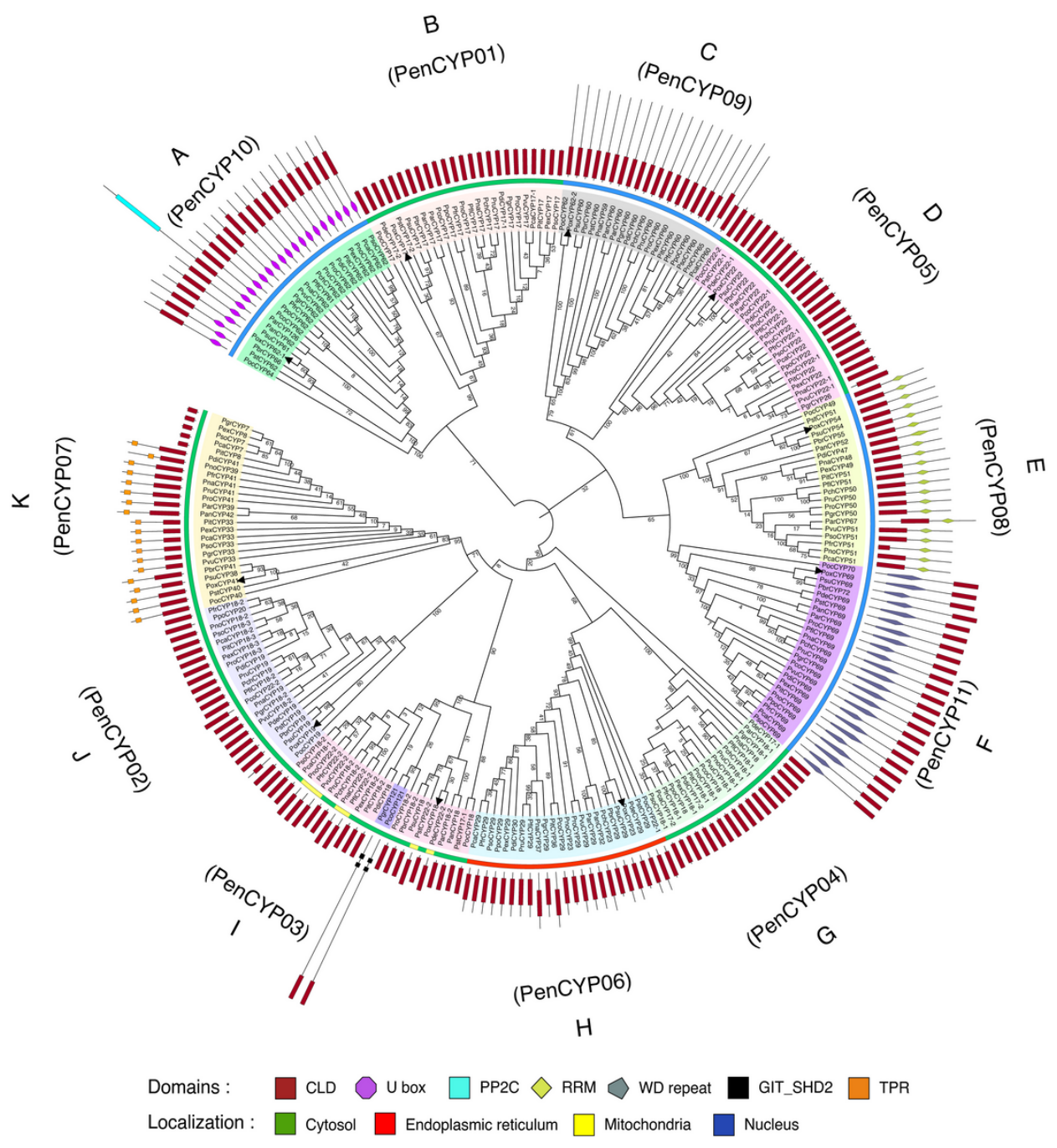

Figure 2

The phylogenetic relationship of different Penicillium cyclophilins. The unrooted tree was generated using the neighbor-joining method in MEGA X. Bootstrap values from 1000 replicates are indicated at each branch. Localization of each member is represented in different colors. Domain architecture of each protein is also shown in the outermost layer. Black triangles represent the Penicillium oxalicum. 
(a)

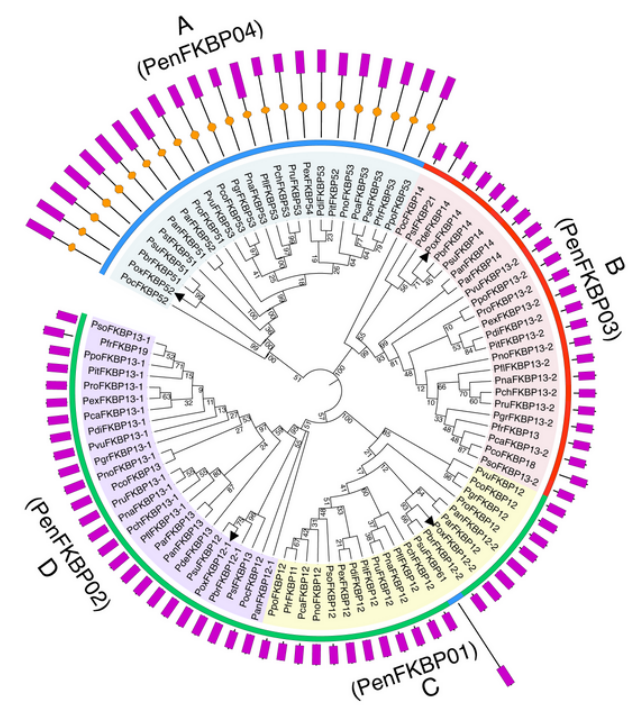

(b)

$\stackrel{\text { A }}{\text { (PenPIN01) }}$

(c)

(PenPTPA02)

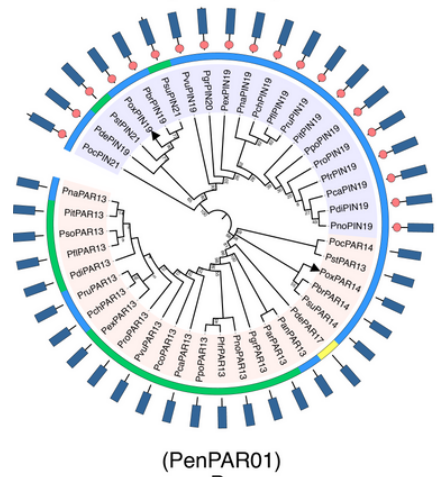

B

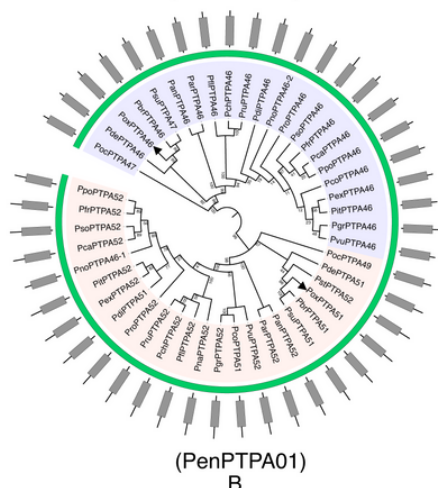

$B$

Domain: FKBP NPL Parulin O Ww PTPA

Localization: Cylosol $\square$ Endoplasmic reticulum $\square$ Mitochondria

Figure 3

The phylogenetic relationship of different Penicillium FKBPs (a), parvulins (b), and protein phosphatase 2A phosphatase activators (PTPAs) (c). The unrooted tree was generated using the neighbor-joining method in MEGA X. Bootstrap values from 1000 replicates are indicated at each branch. Localization of each member is represented in different colors. Domain architecture of each protein is also depicted in the outermost layer. Black triangles represent the Penicillium oxalicum. 
(a)

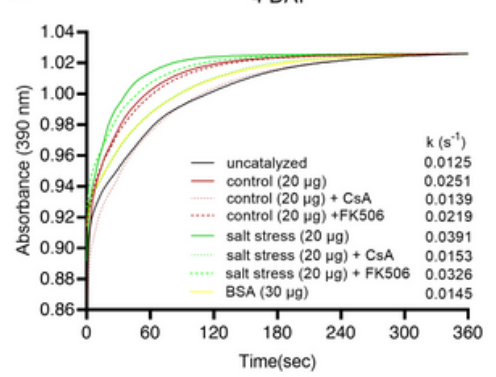

7 DAI

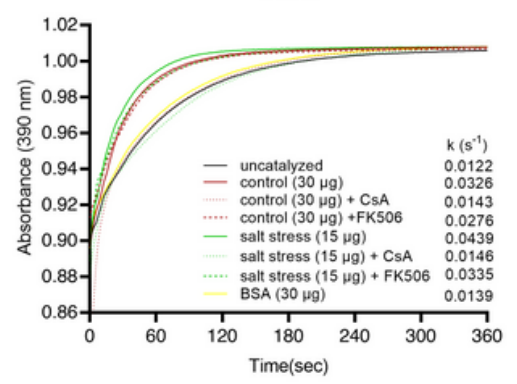

$10 \mathrm{DAl}$

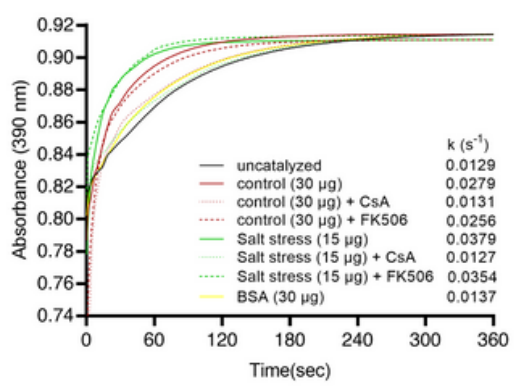

(b)

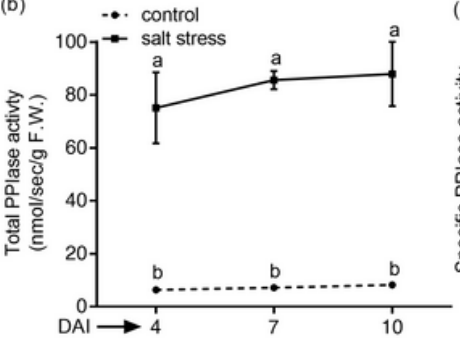

(c)

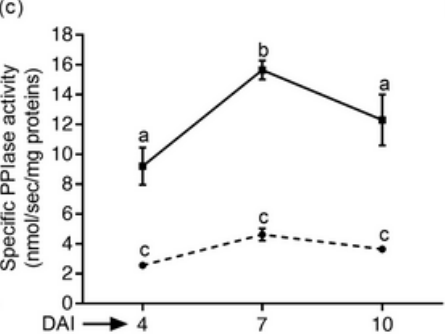

(d)

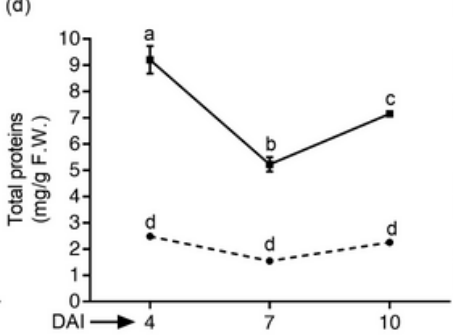

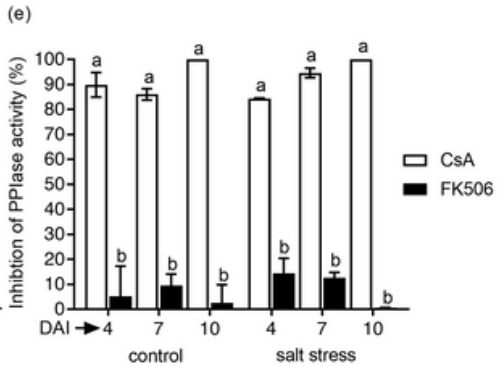

Figure 4

(a) Representative spectra showing the effect of salt stress $(15 \% \mathrm{NaCl})$ on the mycelial peptidyl-prolyl cis-trans isomerase (PPlase) activity of Penicillium oxalicum at 4, 7 and 10 days after inoculation (DAl). The PPlase activity in the crude mycelial extracts was estimated by studying the rate of chymotrypsin catalyzed cleavage of the test peptide, and expressed as the first-order rate constant, k (s-1). Higher first-order rate constant signified greater PPlase activity in the extract. The amount of total proteins used for this assay is given in the parenthesis. Bovine serum albumin (BSA) was used as a negative control. The cyclophilin- and FKBP-associated PPlase activity was estimated by the extent of inhibition in the presence of $100 \mathrm{nM}$ cyclosporin A (CsA) and $2 \mu \mathrm{M}$ FK506, respectively. Control refers to the cultures grown in Sabouraud medium without supplementing with $\mathrm{NaCl}$. Changes in the total (b) and specific PPlase activity (c), and total soluble proteins (d) in the mycelia of Penicillium oxalicum grown in the presence or absence of salt. (e) Effect of cyclosporin A (CsA) and FK506 on mycelial PPlase activity. The values depict the mean of three biological replicates \pm standard error and are significant at P $\leq 0.001$ (Tukey-HSD test; $\alpha=$ 0.05). The values with distinct letters are significantly different. (DAl: days after inoculation). 
PoxCYP18

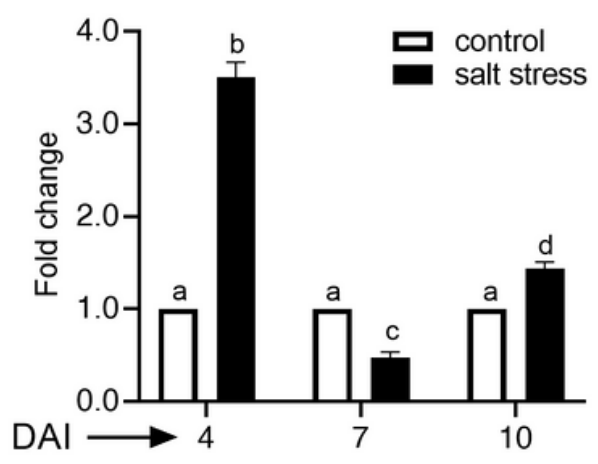

PoxFKBP12-2

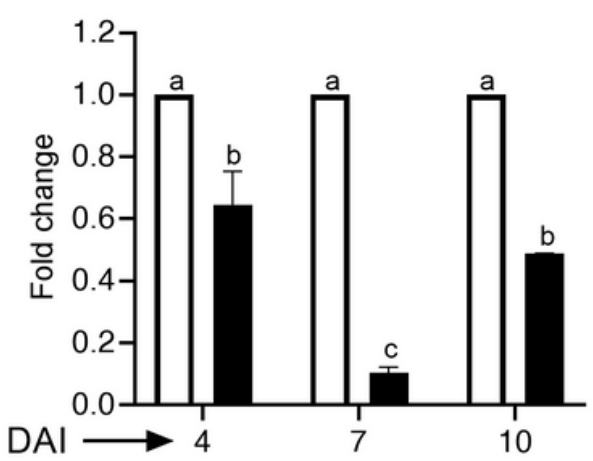

PoxCYP23

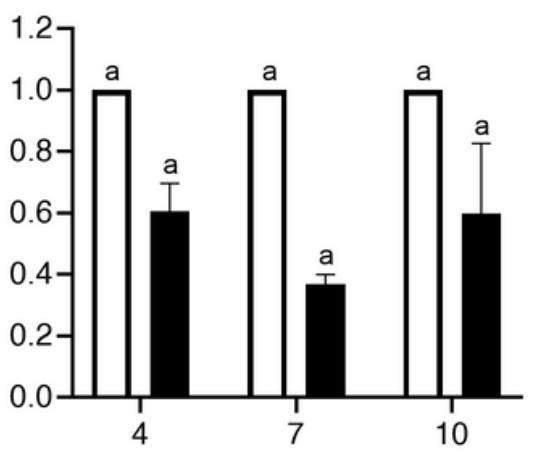

PoxFKBP52

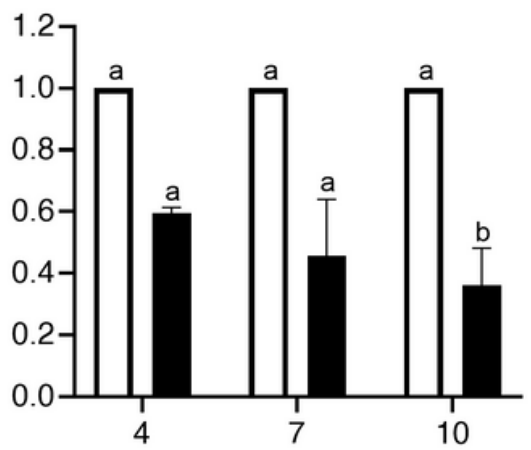

PoxCYP41

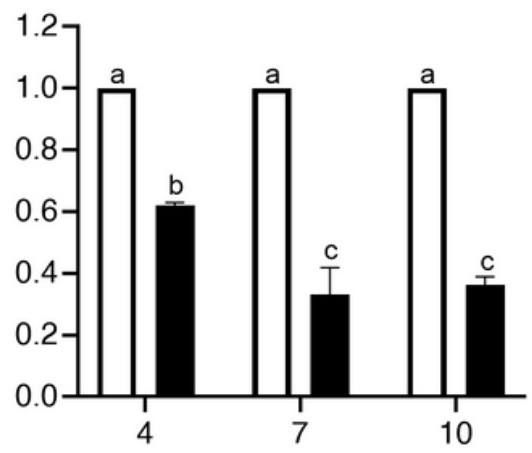

\section{Figure 5}

Effect of salt stress $(15 \% \mathrm{NaCl})$ on expression of cyclophilin and FKBP genes in the mycelia of Penicillium oxalicum. Changes in the transcript levels were estimated by Real-time PCR analysis using ACTIN gene as reference. The fold change presented is with respect to the control lacking NaCl. The values depict the mean of three biological replicates \pm standard error and are significant at $P \leq 0.01$ (Tukey-HSD test; $a=0.05$ ). The values with distinct letters are significally different. (DAl: days after inoculation).

\section{Supplementary Files}

This is a list of supplementary files associated with this preprint. Click to download.

- Supplementarydata.pdf 